OPEN ACCESS

Edited by: Michael W. Kraus,

Yale University, USA

Reviewed by:

Liudmila Liutsko,

Barcelona Biomedical Research Park,

Spain

Stephen Garcia,

University of Michigan, USA

${ }^{*}$ Correspondence:

Nikhila Mahadevan

n.mahadevan@soton.ac.uk

Specialty section:

This article was submitted to Personality and Social Psychology, a section of the journal

Frontiers in Psychology

Received: 14 October 2015

Accepted: 23 February 2016

Published: 30 March 2016

Citation:

Mahadevan N, Gregg AP, Sedikides C and De Waal-Andrews WG (2016)

Winners, Losers, Insiders,

and Outsiders: Comparing

Hierometer and Sociometer Theories

of Self-Regard. Front. Psychol. 7:334

doi: 10.3389/fpsyg.2016.00334

\section{Winners, Losers, Insiders, and Outsiders: Comparing Hierometer and Sociometer Theories of Self-Regard}

\author{
Nikhila Mahadevan ${ }^{*}$, Aiden P. Gregg ${ }^{1}$, Constantine Sedikides ${ }^{1}$ and \\ Wendy G. de Waal-Andrews ${ }^{2}$
}

${ }^{1}$ Centre for Research on Self and Identity, School of Psychology, University of Southampton, Southampton, UK,

${ }^{2}$ Department of Social Psychology, Tilburg University, Tilburg, Netherlands

What evolutionary function does self-regard serve? Hierometer theory, introduced here, provides one answer: it helps individuals navigate status hierarchies, which feature zerosum contests that can be lost as well as won. In particular, self-regard tracks social status to regulate behavioral assertiveness, augmenting or diminishing it to optimize performance in such contests. Hierometer theory also offers a conceptual counterpoint that helps resolve ambiguities in sociometer theory, which offers a complementary account of self-regard's evolutionary function. In two large-scale cross-sectional studies, we operationalized theoretically relevant variables at three distinct levels of analysis, namely, social (relations: status, inclusion), psychological (self-regard: self-esteem, narcissism), and behavioral (strategy: assertiveness, affiliativeness). Correlational and mediational analyses consistently supported hierometer theory, but offered only mixed support for sociometer theory, including when controlling for confounding constructs (anxiety, depression). We interpret our results in terms of a broader agency-communion framework.

Keywords: hierometer theory, sociometer theory, status, inclusion, self-regard, self-esteem, narcissism, assertiveness

\section{INTRODUCTION}

The human self is notoriously hard to pin down. Frustrated, some modern philosophers have questioned its very existence (e.g., Metzinger, 2003). Yet the self still somehow matters: people want their self, whatever it is, to be "good." In other words, they want to achieve positive selfregard (Sedikides and Gregg, 2008). ${ }^{1}$ And understandably so: positive self-regard provokes pleasant feelings whereas negative self-regard provokes painful ones (Gregg et al., 2011).

But why should such a hedonic contingency exist in the first place? Otherwise put, what ultimate function might self-regard serve? Various theories have addressed this question. For

\footnotetext{
${ }^{1}$ The terms self-regard and self-esteem are often used interchangeably. Here, we use the term self-regard as an umbrella term to denote any global evaluation of the self, and the terms self-esteem and narcissism to refer to two types of self-regard. We are not the first to characterize self-esteem and narcissism as alternative ways of evaluating the self; several other researchers have also made this distinction (Baumeister et al., 2003; Kernis, 2003; Paulhus et al., 2004). We elaborate on these distinctions later, but mention them immediately to pre-empt confusion. To anticipate one of our key contentions: we shall argue on theoretical grounds that self-esteem and narcissism serve different functional roles in social life.
} 
example, terror management theory (Pyszczynski et al., 2004) claims that the purpose of self-regard is to buffer the potentially paralyzing terror that humans experience on contemplating death. Alternatively, self-determination theory (Deci and Ryan, 2000) claims that self-regard does not serve any specific purpose, but that its character depends on whether or not the social environment satisfies fundamental needs.

However, perhaps the leading contemporary account of the function of self-regard is provided by sociometer theory (Leary et al., 1995). This posits that self-regard operates as part of an adaptive psychological system that fitted ancestral human beings to social living. In this paper, both to address ambiguities in sociometer theory, and to make new intellectual headway, we introduce a novel alternative account of self-regard's evolutionary function: hierometer theory. We outline the fundamentals about both hierometer theory and sociometer theory and review the empirical evidence for them. We then report on a research program evaluating whether and to what extent patterns of association between variables at three different levels of analysis (social, psychological, behavioral) tend to confirm or infirm each of the theories.

\section{Sociometer Theory: Theoretical Outline}

Sociometer theory starts from the premise that human beings have a fundamental need to belong (Baumeister and Leary, 1995). Satisfying this need is advantageous: group members, when cooperating, afford one another significant opportunities for mutual gain (von Mises, 1963; Nowak and Highfield, 2011; Wilson, 2012). Accordingly, if individuals are excluded from key social networks, their prospects for surviving and reproducing are impaired. It is therefore plausible to hypothesize that a dedicated psychological system evolved to encourage social acceptance (Leary et al., 1995). Such a system would serve two complementary functions, which we here label indicative and imperative.

The indicative function would be to track an individual's level of social acceptance (or, more anthropomorphically, to "monitor" it). Logically, to enjoy the benefits that accrue from mutually supportive relationships, some level of social acceptance is required. To the extent that individuals achieve such social acceptance, they will enjoy higher relational value, defined as the extent to which (they believe that) other group members consider it worthwhile to associate with them (Leary, 1999, 2005). Accordingly, a system designed to track one's social acceptance-in particular, to pick up on interpersonal cues that might portend lower relational value-would be useful. If such cues were detected, the relevant imperative function of the system would be triggered. It would propel an individual to act so as to meet a minimal level of social acceptance. In particular, if social acceptance diverged from this minimum, then the system would seek to reduce this divergence, by prompting an individual to engage in remedial prosocial behaviors.

Sociometer theory contends that self-regard-more specifically, self-esteem-serves both these functions. Initially, it tracks levels of social acceptance, by rising and falling in tandem with them (i.e., its indicative function). A fall in self-esteem sends an intrapsychic signal that one's social acceptance has dropped, perhaps critically. This signal, if sufficiently urgent, motivates individuals to act in ways that restore or reinforce social acceptance (i.e., its imperative function). Thus, the sociometer system is said to operate rather like the digestive system: an empty stomach (cf. low social acceptance) leads to unpleasant hunger pangs (cf. low self-esteem) that prompt one to fill one's stomach by ingesting food (cf. regain social acceptance by acting prosocially). Fundamentally, then, sociometer theory is a theory of insiders and outsiders.

\section{Sociometer Theory: Empirical Evidence}

Sociometer theory enjoys empirical support. In particular, there is good evidence that self-esteem serves its hypothesized indicative function, and mixed evidence that it serves its hypothesized imperative function.

\section{Indicative Function: Tracking Social Acceptance}

Consistent with sociometer theory, self-esteem covaries with perceptions of social acceptance and with levels of social connectivity (Leary et al., 1995; Leary et al., 2001, Study 3; Denissen et al., 2008, Study 5). Self-esteem is also higher to the extent that individuals believe that they possess traits liable to promote social acceptance or social approval (MacDonald et al., 2003; Anthony et al., 2007a). In addition, anticipated levels of self-esteem-after performing various actions, or after various events occur-covary with how individuals expect others will react ( Leary et al., 1995, Studies 1 and 2; Koch and Shepperd, 2008, Studies 3 and 4). Finally, receiving rejection feedback, real or imagined, from personal or impersonal sources, lowers selfesteem (Leary et al., 1998; Zadro et al., 2004; but see Blackhart et al., 2009; Bernstein et al., 2013).

\section{Imperative Function: Prompting Affiliative Behavior}

Consistent with sociometer theory, socially excluded individuals evaluate others more favorably, express a stronger desire to work with them, and report a greater interest in making new friends (Maner et al., 2007). They also conform more to collective opinion (Williams et al., 2000) and tailor their purchases toward products that promote inclusion (Mead et al., 2011). In addition, individuals with low self-esteem opt to join groups only when acceptance in them is guaranteed or undemanding, consistent with their being unwilling to risk further rejection (Haupt and Leary, 1997; Anthony et al., 2007b).

Contrary to sociometer theory, however, social exclusion leads individuals to derogate those who exclude them (Leary et al., 1995; Bourgeois and Leary, 2001), reduces their empathy for and willingness to help others generally (Twenge et al., 2007), and increases their overall levels of hostility and aggression (Twenge et al., 2001; Buckley et al., 2004). Moreover, individuals with low self-esteem are relatively less likely to initiate social interactions and new relationships (Baumeister et al., 2003; Anthony et al., 2007b). Such anti-social reactions seem unlikely to promote social acceptance or augment relational value. 


\section{Hierometer Theory: Theoretical Outline}

Like sociometer theory, hierometer theory proposes that selfregard serves an evolutionary function. Unlike sociometer theory, it proposes that this function is to navigate status hierarchies. Specifically, hierometer theory proposes that selfregard operates both indicatively-by tracking levels of social status-and imperatively-by regulating levels of status pursuit (Figure 1).

Status hierarchies are pervasive (Sidanius and Pratto, 1999; Sapolsky, 2005). They exist in both humans and animals, in simple and complex societies, and in formal and informal groups (Mazur, 1985; Anderson et al., 2001, 2006). Moreover, these hierarchies matter: higher-status individuals enjoy better health and well-being (Marmot, 2004; Sapolsky, 2005), a wider choice of romantic partners (Betzig, 1986), and greater reproductive success (von Rueden et al., 2008, 2011).

Given the significance of status hierarchies, a dedicated psychological system is liable to have evolved to help individuals navigate them successfully (cf. Gilbert, 2000; Sloman, 2008). Certainly, high status is desirable given the benefits it brings, and the desire to achieve it is often considered fundamental (Barkow, 1975, 1980; Frank, 1985; Marmot, 2004; Anderson et al., 2015). Nonetheless, the indiscriminate pursuit of ever higher status is not adaptive. This is because competing for status involves entry into zero-sum contests that can be lost as well as won. Accordingly, the pursuit of status is risky. Potential costs range from the psychologically uncomfortable (Ridgeway and Berger, 1986) to the physically lethal (Wrangham and Wilson, 2004). The upshot is that individuals must pursue status judiciously.

Consider, by analogy, the game of poker (Sklansky, 1994). Here, players compete to win a pot of money. Each player is dealt a private hand of cards, some of which, in certain combinations, are of higher value than others, leading to "good hands" versus "bad hands." One player begins the round by placing a bet, and all players then respond in turn. Each player may either raise (i.e., increase the amount bet), fold (i.e., opt out of the round, losing the amount bet), or check (i.e., stay in the game, matching the amount bet). The round continues until only one player remains, who then wins the pot, or until two or more players remain, in which case the player with the best hand then wins the pot in a public showdown.

In poker, players play each round by considering their own cards, their opponents' likely cards, and the relevant stakes. On this basis, they decide to raise or fold (checking being the intermediate option). Similarly, in social life, individuals navigate status hierarchies by considering their own abilities, their opponents' likely abilities, and the costs and benefits of competition. On this basis, they decide whether or not to enter a contest, and whether or not to persist in it. In poker, players generally adopt the strategy of raising when their hands seem comparatively good, and folding when their hands seem comparatively poor. That is, they "know when to hold 'em, know when to fold 'em" (Schlitz, 1978). Similarly, in social life, people generally adopt the strategy of engaging in contests they expect to win and avoiding contests they expect to lose (Sloman and Price, 1987; Gilbert et al.,
1995). That is, individuals, based on their best reckonings, either escalate (i.e., intensify) contests or de-escalate (i.e., defuse) contests. In humans, escalation requires more assertive behavior, whether in attack or defense; de-escalation, in contrast, requires more acquiescent behavior, whether in surrender or withdrawal. These alternative behavioral strategies have also been termed hawk and dove (Maynard Smith, 1982). The former offers higher reward at greater risk, the latter lower reward at lesser risk. Both can be adaptive, depending on the circumstances.

Hierometer theory proposes that higher self-regard prompts the adoption of more hawkish strategies, and lower self-regard the adoption of more dovish ones. As such, self-regard is part of a dedicated system that evolved to regulate behavior adaptively when navigating status hierarchies. To be adaptive, self-regard must predict the relative success of hawkish strategies when higher, and of dovish strategies when lower. Logically, this can only be the case if self-regard does indeed track some characteristic that predicts the relative success of those strategies. What could that characteristic be? Social status is a leading contender. Here, we define it as the respect, admiration, and importance that society at large confers upon an individual (Magee and Galinsky, 2008; Fiske, 2010; Huo et al., 2010). Higher-status individuals can afford to adopt more hawkish strategies. This is because, in order for them to have attained higher status in the first place, several factors would have had to operate in their favor. Such factors might have included a fund of pre-existing resources to draw on (Magee and Galinsky, 2008), or a superior ability to produce goods and services (Klein, 2010). Where present, such propitious factors would objectively increase the likelihood that adopting a hawkish strategy - that is, escalating contests through assertive behaviorwould work better. In poker terms, higher-status individuals would hold a "good hand," making it more adaptive for them to "raise." However, where such factors are absent, as they often are among lower-status individuals, a dovish strategyde-escalating contests through acquiescent behavior-would work better. In poker terms, lower-status individuals would hold a "poor hand," making it more adaptive for them to "fold."

Note here some key differences between hierometer theory and dominance theory (Barkow, 1975, 1980), another alternative to sociometer theory (e.g., Leary et al., 2001). Dominance theory, plausibly interpreted, states that self-esteem tracks, not levels of social acceptance or relational value, but instead levels of "dominance" or "prestige," by which some social or psychological, rather than behavioral, construct is meant. For example, according to Barkow (1975), "[to] evaluate the self as higher than others is to maintain self-esteem ( $p$. 554)" and "[...] approbation and respect permit the self to evaluate itself as being of higher standing than others, thereby maintaining self-esteem (p. 555-556, italics added)." Barkow (1980) proposes that people pursue various "prestige strategies" to maintain their standing, and draws analogies with social rank in other species. Accordingly, the term "status" might be reasonably substituted for "dominance" or "prestige" here, especially given the key role that attention 
and respect play in Barkow's characterization (Anderson et al., 2001, 2006; Fiske, 2010). If so, then dominance theory, like hierometer theory, states that higher social status promotes higher self-esteem. However, insofar as dominance theory emphasizes the critical importance of social status for reproductive success, it can be interpreted as proposing that self-regard operates homeostatically, motivating individuals to attain and maintain sufficient levels of social status (Anderson et al., 2015), much as sociometer theory proposes happens with respect to levels of social inclusion (Baumeister and Leary, 1995). In contrast, hierometer theory proposes that self-regard operates non-homeostatically, regulating the behavior strategies that individuals adopt so that they match rather than modify their current status. Hence, dominance theory and hierometer theory make distinct predictions. The former predicts that lower self-regard, tracking lower status, should lead to increased behavioral assertiveness, as a form of adaptive compensation. The latter predicts that lower self-regard, tracking lower status, should lead to increased behavioral acquiescence, as a form of adaptive consolidation. Thus, hierometer theory, far from being a restatement of dominance theory, is an empirically testable alternative to it.

In brief, hierometer theory proposes that self-regard acts as a crucial psychological mediator: it bridges the gap between social status and assertive behavior by tracking the former and regulating the latter, thereby enabling individuals to navigate status hierarchies, as their status best allows. Fundamentally, then, hierometer theory is a theory of winners and losers.

\section{Hierometer Theory: Existing Evidence}

Hierometer theory already enjoys some empirical support. Assorted findings are consistent with self-regard serving both its hypothesized indicative and imperative functions.

\section{Indicative Function: Tracking Social Status}

Socioeconomic indicators (i.e., income) modestly predict trait self-esteem (Twenge and Campbell, 2002). In addition, state self-esteem increases or decreases respectively when students are notified of academic successes or failures (Crocker et al., 2002, 2003), when job candidates encounter a more or less smartly dressed competitor (Morse and Gergen, 1970), and when participants are assigned to the roles of supervisors or subordinates (Wojciszke and Struzynska-Kujalowicz, 2007, Study 2). Finally, from a neurological point of view, some brain circuits seem to be specialized to identifying one's place in the status hierarchy (Zink et al., 2008).

\section{Imperative Function: Regulating Assertive Behavior}

Trait self-esteem positively predicts self-reports of more assertive behavior ("interpersonal dominance"), both on standard questionnaires (Leary et al., 2001) and on behavioral vignettes (De Waal-Andrews, 2012, unpublished). In addition, when participants are alternately instructed to recall occasions on which they "felt secure in their selfworth" versus "felt like a failure"-thereby manipulating their state self-esteem-they recall more assertive behaviors and acquiescent behaviors respectively (De Waal-Andrews, 2012, unpublished).

Several studies also show that higher and lower self-regard are respectively associated with the adoption of more risk-seeking and risk-averse strategies. For example, individuals with higher self-esteem prefer risky gambles over certain gains on a monetary task (Josephs et al., 1992), at least when potentially regretinducing feedback on foregone options is offered. Moreover, when telling a joke or completing a creativity test, they are more likely to "go for gold" than to "play it safe"-an effect amplified under conditions of psychological threat (Landau and Greenberg, 2006). Individuals with high self-esteem also make riskier personal decisions on interpersonal vignettes even controlling for trait anxiety, with the effect being partly mediated by success expectancies and failure-related feelings (Wray and Stone, 2005).

\section{The Sociometer and the Hierometer: Toward Conceptual Coordination}

How do sociometer theory and hierometer theory relate to one another? Are they antagonistic or complementary? The answer, it turns out, hangs on how one interprets sociometer theory, and on which formulation of it one emphasizes, for one ends up dealing with theoretical constructs that are broader or narrower in scope, and defined with greater or lesser precision. Our summary of sociometer theory above blends (intentionally) two versions of the theory, original and revised.

The original version of sociometer theory (Leary and Downs, 1995; Leary et al., 1995) emphasizes how self-esteem tracks social acceptance, by which is implied some sort of community belongingness, or social inclusion. For example, Leary (2004, p. 374), recounting the original version, states that "only those who have established mutually supportive relationships with people can count on others' assistance in terms of food sharing, physical protection, and care when ill, injured, or old. An individual who does not maintain a minimal level of social acceptance is at a decided disadvantage compared to one who is warmly accepted [...] humans [...] possess a strong and pervasive need for acceptance and belongingness [...] [italics added]."

In contrast, the revised version (Leary and Baumeister, 2000) emphasizes how self-esteem tracks relational value, defined as the degree to which other people regard their relationship with the individual as important or valuable overall, for whatever reason. For example, Leary (2005, p. 86) states that "Many kinds of events can lower people's self-esteem-failure, rejection, embarrassing situations, negative evaluations, being outperformed by others, and so on-but, from the standpoint of sociometer theory, these all involve events that potentially lower people's relational value in the eyes of others [italics added]" (see also Kirkpatrick and Ellis, 2001; Leary et al., 2001, p. 907).

Accordingly, the revised version of sociometer theory is pitched at a broader level of analysis than the original version is. Relational value, as a construct, is broad enough to cover 
any reason for self-esteem's rising and falling that involves social interaction. However, social inclusion, as a construct if understood as community belongingness, is narrower, and excludes many such reasons. In particular, one can enjoy high status, by being respected or admired for being competent, without enjoying high inclusion, by being liked or loved for being warm-and vice versa (Cuddy et al., 2008). However, the evidence suggests that status, so conceived, can affect selfesteem independently of inclusion, so conceived (e.g., Leary et al., 2001: Study 1; Koch and Shepperd, 2008). Consequently, the original version of sociometer theory cannot account for such findings, only the revised version. More generally, the original version characterizes self-esteem primarily in terms of the superdimension of communion, which comprises such factors as inclusion, warmth, and affiliativeness, rather than in terms of the (orthogonal) super-dimension of agency, which comprises such factors as status, competence, and assertiveness (Foa, 1961; Wiggins, 1979; McCrae and Costa, 1989; Moskowitz, 1994; Cuddy et al., 2008; Huo et al., 2010). This is problematic, because self-esteem may actually be more agency-based. For example, Wojciszke et al. (2011) found that self-ascribed agentic traits (e.g., "clever") predicted self-esteem better than self-ascribed communal traits (e.g., "good-natured"; though see Gebauer et al., 2013, for some moderators). In addition, Zeigler-Hill (2010) reported that eight standard measures of self-regard were at least as strongly linked to agentic traits as they were to communal ones.

Hence, it is important to be theoretically precise about self-esteem's agentic role. The original version of sociometer theory neglects it by emphasizing community belongingness. The revised version partly rectifies this neglect by allowing for the possibility of many types of relational value. However, the revised theory still does not specify the details of selfesteem's agentic role, nor does it differentiate self-esteem's agentic role from its communal role. Hierometer theory breaks new theoretical ground by specifying precisely how (social) status, (psychological) self-esteem, and (behavioral) assertiveness might interact as part of an evolutionarily adaptive system. Moreover, with this agentic role specified, the communal role played by self-esteem comes into sharper focus. In particular, the original version of sociometer theory can be plausibly interpreted as specifying precisely how (social) inclusion, (psychological) selfesteem, and (behavioral) affiliativeness might interact as part of evolutionarily adaptive system. Thereafter, it becomes possible to empirically test whether and to what extent these agentic and communal roles are supported or refuted by patterns of empirically observed correlations.

A further virtue of hierometer theory's specificity is that, in clearly distinguishing between different levels of analysis, including in the original version of sociometer theory, it encourages the operationalization of constructs at corresponding levels, a finesse that some prior research has not observed. For example, Koch and Shepperd (2008), in testing how well-acceptance (i.e., inclusion) and competence independently predicted self-esteem, although they tested a communal construct against an agentic one, nonetheless confounded social and psychological levels of analysis, respectively. Arguably, they should have tested how inclusion versus status, or competence versus warmth, predicted self-esteem. In addition, Anthony et al. (2007a), when testing how well different types of traitsnamely, "communal qualities" versus "social commodities"independently predicted self-esteem, listed "popular" and "social status" as examples of the latter. However, popularity and status are not only psychological in nature, but also social.

\section{Hierometer Theory: Encompassing Narcissism Too}

We have so far alternated between using the term "selfregard," mainly in respect of hierometer theory, and the term "self-esteem," mainly in respect of sociometer theory. And intentionally so: for self-regard is a broader construct than selfesteem, and hierometer theory explicitly allows for the possibility that other types of self-regard might serve its prescribed indicative and imperative functions. We have one particular candidate in mind: narcissism.

Narcissism, for our purposes, is a normally distributed trait, and may be regarded as the continuous subclinical counterpart of the categorical personality disorder (Baumeister et al., 2003; Kernis, 2003; Campbell and Foster, 2007; Miller et al., 2014). Its antecedents, correlations, and consequences have been extensively researched (Paulhus et al., 2004; Rhodewalt and Peterson, 2009; Campbell and Miller, 2011), often in conjunction with self-esteem (Sedikides et al., 2004; Lee et al., 2013, Study 1). As most commonly operationalized (but see Pincus et al., 2009, for one of several alternatives), narcissism entails an interest in leadership and authority, a propensity for grandiosity and exhibitionism, and a sense of entitlement combined with a manipulative streak (Raskin and Hall, 1981; Ackerman et al., 2011). In romantic relationships, moreover, narcissists prefer being admired over being loved, pursue shortterm rather than long-term relationships, and evaluate mates based on external characteristics rather than inner qualities (Campbell, 1999; Brunell and Campbell, 2011; Holtzman and Strube, 2011). Accordingly, narcissism has been hypothesized to involve a surfeit of agency alongside a deficit in communion (Campbell et al., 2002; Sedikides et al., 2002; Morf et al., 2011).

If this characterization is correct, then one might expect narcissism to be particularly likely to track social status and regulate assertive behavior, as hierometer theory specifies. Conversely, one might expect narcissism to be less likely to track social inclusion and regulate affiliative behavior, as sociometer theory specifies. Thus, hierometer theory, by encompassing narcissism too, opens up fruitful avenues for empirical investigation (cf. Back et al., 2009) and adds to the literature exploring narcissism's evolutionary origins (Holtzman and Strube, 2011).

It should be noted that attempts have been made to account for narcissism in terms of sociometer theory. In particular, narcissism in this connection has been described as a dysfunction, where those who exhibit it believe that "others regard them more favorably and accept them more enthusiastically than is, in fact, the case" (Leary and Downs, 1995, p. 138). In other words, levels of self-regard in narcissists are no longer an accurate guide to their objective levels of social inclusion or relational value. But 
if so, then sociometer theory does not so much account for narcissism as undergo qualification in the light of its existence; for in narcissists, self-regard does not function as sociometer theory prescribes. In contrast, hierometer theory offers a positive and constructive account of the function of narcissism, which can be put to the empirical test.

To be clear, we regard self-esteem as the prototypical form of self-regard, and thus the primary construct to consider in evaluating functional theories. Nonetheless, narcissism is still perhaps the best known subtype of self-regard, and its concurrent consideration-especially given the affinity between the agentic emphasis of hierometer theory and the agentic roots of narcissism-is well-justified, and potentially enlightening.

\section{Goals and Features of the Current Research}

Here, we report a systematic program of correlational research with several interlocking goals and features.

First, the research program is designed to test hierometer theory, by examining whether and to what extent its core constructs-status, self-regard, and assertiveness-interrelate as predicted. Second, it is designed to test sociometer theory in an exactly parallel manner. Do its core constructs-inclusion, selfregard, and affiliativeness-also interrelate as predicted? Third, the program operationalizes relevant constructs at various levels of analysis, by distinguishing among two types of social relations (i.e., status, inclusion), psychological self-perception (i.e., selfesteem, narcissism), and behavioral strategy (i.e., assertiveness, affiliativeness). Fourth, the program features a comprehensive analytic approach, to meet the goals above. To begin with, it looks at simple and partial correlations between (a) social relations and self-regard, and (b) self-regard and behavioral strategy. This permits separate tests of whether the data support or refute the indicative and imperative functions hypothesized by hierometer theory and sociometer theory. Fifth, the program proceeds to test-for the first time we believe-whether and to what extent self-regard mediates the link between social relations and interpersonal behavior, as hierometer theory and sociometer theory respectively predict. Sixth, in testing the above, the program investigates self-regard, not only in its standard form as self-esteem, but also in a grandiose form as narcissism. Finally, the program proceeds to investigate whether and to what extent any empirically confirmed links to self-esteem continue to obtain after statistically controlling for clinical variables known to overlap with self-esteem - in particular, depression and anxietywhich have themselves, in the context of evolutionary theory, been hypothesized to serve similar indicative and imperative functions (Price et al., 1994; Sloman, 2008).

It should be understood that this program of research represents the first step in a process of validating hierometer theory in the comparative context of sociometer theory. It allows for the possibility that patterns could emerge that are at odds with one or both theories, and enables tests of whether the data fit one theory better than another or both equally. Note that a complementary program of experimental research is also underway to test the hypothesized causal pathways between the social, psychological, and behavioral variables more definitively. For example, Mahadevan et al. (2015) found that expectations of higher and lower future social status or inclusion-both manipulated via bogus test feedback-independently led to higher and lower self-esteem, thereby validating the indicative functions of self-esteem specified by both hierometer theory and sociometer theory.

\section{Hypotheses}

In sum, in regards to hierometer theory, we hypothesized that status would correlate positively with self-esteem as well as narcissism; that self-esteem and narcissism would each correlate positively with assertiveness; and that self-esteem and narcissism would each mediate the link between status and assertiveness. In regards to sociometer theory, we hypothesized that inclusion would correlate positively with self-esteem. Evidence for the link between self-esteem and affiliativeness is mixed. However, as low self-esteem is theorized to prompt greater affiliativeness in order to repair levels of social inclusion, we tentatively hypothesized that self-esteem would correlate negatively with affiliativeness. Furthermore, we hypothesized that self-esteem would mediate the link between inclusion and affiliativeness.

\section{MATERIALS AND METHODS}

\section{Overview}

We conducted two studies. Each featured shared and unique elements. The shared elements were designed repeatedly to test our focal hypotheses concerning hierometer theory and sociometer theory. To this end, both studies assessed social relations (status and inclusion), psychological selfperception (self-esteem and narcissism), and behavioral strategy (assertiveness and affiliativeness). The unique elements of the studies were designed to rule out plausible alternative hypotheses and to advance theoretical understanding. To this end, Study 1 also assessed depression, and Study 2 additionally also anxiety. Regarding the shared elements of both studies, we present their associated analyses in parallel. This makes for greater brevity and permits the replicability of findings to be scrutinized. Regarding the unique elements of both studies, we present their associated analyses in sequence. This makes for a systematic analytic progression.

\section{Platform, Procedure, Precautions, and Participants}

All studies were run online. They were created and administered using the designated university internet survey software. Participants were recruited via CrowdFlower ${ }^{\mathrm{TM}}$, a leading crowdsourcing site, and took part for a nominal fee, on condition they were aged 18 years or above and were fluent in English. Before taking part, participants read some introductory information and indicated their consent; afterward, they read a debriefing statement. The studies were approved by the Research Ethics Committee of the University of Southampton, UK.

Crowdsourcing typically yields high-quality data, both rapidly and cheaply, from diverse participants (Buhrmester et al., 2011; 
Germine et al., 2012). Nonetheless, it is prudent to exclude participants whose data are, for any of several reasons, suspect. Here, we excluded participants if: (a) their IP address appeared more than once in the dataset (suggesting multiple completions); (b) they completed the survey in less than half the median survey time (suggesting an absence of reflection); (c) they completed all items identically on any questionnaire featuring both forwardscored and reverse-scored items (suggesting mindless buttonclicking); (d) their self-reported English-proficiency was poor or very poor; (e) they were younger than 18; and (f) they omitted to answer more than $5 \%$ of questionnaire items.

Table 1 shows sample demographics before and after screening, and the percentage excluded for each reason. As some participants were excluded for multiple reasons, the sum of the individual percentages excluded exceeds the total percentage. Over $85 \%$ of the original participants were retained. Of these, about two-thirds were female, nine-10ths resident in the USA, and the majority aged between 20 and $40 .^{2}$ We report analyses conducted on screened data, although analyses conducted on unscreened data yielded inferentially equivalent results.

\section{Measures}

\section{Social Relations}

We assessed status and inclusion, respectively, with structurally validated 8 - and 9-item scales. These scales were originally developed by Huo et al. (2010) and enhanced by Mahadevan et al. (2015) with additional items that gave a broader conceptual coverage and achieved a superior factor solution. Each item began with the stem "Most of the time I feel that people..." and ended with a different sentence completion (e.g., status: "... see me as

${ }^{2}$ Given that Gebauer et al. (2013) found a stronger correlation between self-esteem and self-ascribed agentic traits (e.g., ambitious) for men, and between self-esteem and self-ascribed communal traits (e.g., caring) for women, we also tested whether gender moderated the suite of effects we report below. In general, equivalently significant and substantial effects were obtained for both genders. Given the exposition is already lengthy, interested readers may contact the authors for further details.

TABLE 1 | Participant profile.

\begin{tabular}{lcc}
\hline Variable & Study $\mathbf{1}$ & Study 2 \\
\hline Total sample size & $\mathbf{7 1 2}$ & $\mathbf{7 8 9}$ \\
Duplicate IP addresses & $2.7 \%$ & $2.9 \%$ \\
Age <18 years & $0.8 \%$ & $1.0 \%$ \\
Poor reported English & $0.7 \%$ & $1.4 \%$ \\
proficiency & & \\
Overly rapid completion (< half & $3.7 \%$ & $5.8 \%$ \\
median completion time) & & \\
$>5 \%$ blank & $4.8 \%$ & $4.2 \%$ \\
Stereotyped responses & $2.5 \%$ & $3.7 \%$ \\
Total excluded & $\mathbf{1 2 . 1} \%$ & $\mathbf{1 3 . 8} \%$ \\
\hline Screened sample size & $\mathbf{6 2 6}$ & $\mathbf{6 8 0}$ \\
Gender (male) & $37.5 \%$ & $39.1 \%$ \\
Mean age (in years) & 34.5 & 32.3 \\
SD age (in years) & 12.9 & 12.8 \\
U.S. residence & $91.2 \%$ & $86.5 \%$
\end{tabular}

an important person”; inclusion: “. . like me as a person”). Both scales featured a five-point response format $(1=$ strongly disagree, $5=$ strongly agree).

\section{Psychological Self-Regard}

We assessed self-esteem with the 10-item Rosenberg Self-Esteem Scale (RSES; Rosenberg, 1965). We assessed narcissism with one of two versions of the Narcissistic Personality Inventory: the original 40-item (multifactorial) version (NPI-40: Raskin and Hall, 1981; Studies 1 and 3) or the abbreviated (unifactorial) 16item version (NPI-16; Ames et al., 2006; Study 2). ${ }^{3}$ Both the RSES and the NPI are leading measures of self-regard (Byrne, 1996; Twenge et al., 2008). The RSES featured a five-point response format ( 1 = strongly disagree, $5=$ strongly agree $)$, and the NPI a six-point sliding scale, located between bipolar options (cf. Lee et al., 2013). Sample items: "I feel that I have a number of good qualities" (RSES); "I know that I am good because everybody keeps telling me so" versus "When people compliment me I sometimes get embarrassed" (NPI).

\section{Behavioral Strategy}

We assessed assertiveness and affiliativeness using the 48item Social Behavior Inventory (SBI; Moskowitz, 1994). The SBI consists of four 12-item subscales that respectively assess behaviors originally labeled dominant, submissive, agreeable, and quarrelsome (although we prefer the labels assertive, acquiescent, affiliative, and alienating, which emphasize interpersonal action over individual disposition, and avoid conceptual confounds [e.g., dominant implies a social rank]). The SBI featured a six-point response format $(1=$ very unlike me, $6=$ very like me). Sample items: "I speak in a clear, firm voice" (dominant); "I do not express disagreement" (submissive); "I compliment or praise other people" (agreeable); and "I criticize others" (quarrelsome). To derive an overall assertiveness index, we subtracted participants' mean score on the submissive subscale from their mean score on the dominant subscale; to derive an overall affiliativeness index, we subtracted participants' mean score on the quarrelsome subscale from their mean score on the agreeable subscale.

\section{Depression}

We assessed depression in two ways: with the 21-item Beck Depression Inventory-II (BDI-II; Beck et al., 1996) and with the 20-item Centre for Epidemiological Studies Depression Scale (CES-D; Radloff, 1977). The BDI-II lists different symptoms, followed by topic-specific response options each time. Sample item: "Sadness": $(1=I$ do not feel sad; $2=I$ feel sad some of the time; $3=I$ am sad all the time; $4=I$ am so sad or unhappy I can't stand it). The CES-D lists different statements about

\footnotetext{
${ }^{3}$ Given the multifactorial nature of the NPI-40 in Study 2, we also tested whether the effects we report below obtained similarly or differently for the three key facets of narcissism isolated by Ackerman et al. (2011), namely, leadership/authority, grandiosity/exhibitionism, and exploitativeness/entitlement (see also Lee et al., 2013). Although effects obtained for overall narcissism ultimately replicated across all facets, exploitativeness/entitlement was less strongly related to agentic variables (e.g., status, assertiveness), and more negatively related to communal variables (e.g., inclusion, affiliativeness). Again, given the length of the exposition, interested readers are encouraged to contact the authors for further details. The unifactorial nature of the NPI-16 obviated any such supplementary analysis in Study 1.
} 
symptoms, followed by standard response options. Sample item: I was bothered by things that usually don't bother me" $(1=$ Never or hardly ever; $2=$ Occasionally, now and then; $3=$ A good deal of the time; $4=$ Mostly or all of the time). Given the high correlation between the BDI-II and the CES-D, $r(624)=0.85, p<0.0001$, we created a single composite measure, by standardizing scores on each and averaging the result.

\section{Anxiety}

We assessed anxiety in two ways: with the 21-item Beck Anxiety Inventory (BAI; Beck et al., 1988) and with the 20-item trait version of the State Trait Anxiety Inventory (STAI; Spielberger et al., 1983). Both measures cover a range of anxiety symptoms (e.g., nervousness, light-headedness, trembling), are suitable for clinical and non-clinical samples, and feature four-point response formats. The BAI lists the names of different anxiety symptoms, and has respondents indicate their severity. Sample item: "Numbness or tingling" ( $1=$ NOT AT ALL: It didn't bother me in the slightest; 2 = MILDLY: It didn't bother me much; 3 = MODERATELY: It wasn't pleasant at times; and $4=$ SEVERLY: It bothered me a lot). The STAI lists different statements about dispositional anxiety, and has respondents indicate their level of agreement. All statements began with the sentence stem "In general...." Sample item: “...I worry over possible misfortunes" $(1=$ Not at all $; 2=$ A little; $3=$ Somewhat; and $4=$ Very much so). Again, given the high correlation between the BAI and the STAI, $r(678)=0.64, p<0.0001$, we created a single composite measure, by standardizing scores on each and averaging the result.

\section{RESULTS AND DISCUSSION}

\section{Descriptive Statistics}

Table 2 summarizes the key aspects of all measures (means, standard deviations, internal consistencies, deviations from midpoint). In no case did any measure fall short of conventional psychometric desiderata. Moreover, no variable evinced a distribution that was atypical for everyday populations (e.g., levels of self-esteem were significantly higher than the midpoint, and levels of narcissism were significantly lower than the midpoint).

\section{Indicative Function: Social Relations and Psychological Self-Regard}

Both hierometer theory and sociometer theory predict that levels of psychological self-regard will track levels of social relations (i.e., serve an indicative function). Hierometer theory specifically predicts that higher status will lead to higher self-regard, either as self-esteem or narcissism. Sociometer theory, in its original version, specifically predicts that higher inclusion will lead to higher self-regard in the form of self-esteem, though it makes no prediction concerning narcissism (but see Leary and Downs, 1995). However, to the extent that narcissism, unlike regular self-esteem, entails an agentic surfeit and a communal deficit, narcissism should disproportionately track status over inclusion, whereas self-esteem should track both more equitably.
The upper panel of Table 3 lists all correlations between the two social relations variables (i.e., status and inclusion) and the two self-regard variables (i.e., self-esteem and narcissism). These appear in two forms: raw (first row) and partialed (second row). The partial correlations between any pair of variables (e.g., status and narcissism) controlled for overlapping variance attributable to the other pair (e.g., inclusion and self-esteem).

Several patterns deserve note. First, all raw coefficients were significantly positive. At first glance, then, the data are consistent with both forms of self-regard simply tracking both forms of social relations. The higher participants' status or inclusion, the higher their self-esteem or narcissism was too. Second, the same raw coefficients were, within each study, always higher for selfesteem than for narcissism. This suggests that self-esteem is, overall, a more sensitive tracker of both status and inclusion. Third, the raw coefficients were, within each study-and broken down by self-esteem and narcissism individually-always at least somewhat higher for status than for inclusion. This suggests that self-regard tracks status at least as sensitively as inclusion. Finally, the difference in raw coefficient size for correlations with status and inclusion was greater for narcissism than it was for selfesteem. This suggests that, compared to self-esteem, narcissism is a relatively more sensitive tracker of status than inclusion (while being an absolutely less sensitive tracker of both).

Nonetheless, status and inclusion correlated positively in both studies-respective $r s=0.64$ and $0.63, p s<0.0001$-as did self-esteem and narcissism-respective $r s=0.43$ and 0.30 , ps $<0.0001$. Accordingly, we examined the partialed coefficients to gage the crucial links between the statistically "purified" variables.

Although predictably lower in magnitude, all partial coefficients nonetheless remained positive and significant-with one key and consistent exception: narcissism now correlated negatively with inclusion, and significantly so in one out of two studies. This suggests that, if anything, narcissism tracks decrements in inclusion by increasing, not by decreasing (like self-esteem). This novel finding underscores the value of assessing self-regard in two different ways, and raises the possibility that any functional link between self-regard and inclusion may not be monolithic and unidirectional. The overall picture is that, whereas self-esteem increases with better social relations generally, narcissism increases with one form (status) but decreases with the other form (inclusion). Otherwise, the patterns obtained with partialed coefficients mirrored those obtained with raw coefficients, suggesting identical conclusions.

In all, the patterns obtained were consistent with selfregard serving the indicative functions specified by hierometer theory (i.e., for self-esteem and narcissism) and by sociometer theory (i.e., for self-esteem). Importantly, however, both forms of self-regard independently covaried with status at least as much as with inclusion; accordingly, self-regard, if it tracks social relations, seems not only to track community belongingness, but also and no less sensitively, achievementrelated standing. Moreover, the inverse link between narcissism and inclusion complicates the empirical picture: it suggests a new and unanticipated type of indicative function, not easily accounted for in terms of the original version of 
TABLE 2 | Means, standard deviations, and reliabilities of main variables.

\begin{tabular}{|c|c|c|c|c|c|c|c|}
\hline \multirow[b]{2}{*}{ Measures } & \multirow[b]{2}{*}{ Scale } & \multicolumn{3}{|c|}{ Study 1} & \multicolumn{3}{|c|}{ Study 2} \\
\hline & & $M$ & $S D$ & $\alpha$ & $M$ & $S D$ & $\alpha$ \\
\hline Status & $1-5$ & $3.21 \uparrow$ & 0.75 & 0.91 & $3.33 \uparrow$ & 0.75 & 0.91 \\
\hline Inclusion & $1-5$ & $3.68 \uparrow$ & 0.71 & 0.93 & $3.75 \uparrow$ & 0.67 & 0.92 \\
\hline Self-esteem & $1-5$ & $3.59 \uparrow$ & 0.84 & 0.92 & $3.61 \uparrow$ & 0.79 & 0.91 \\
\hline Narcissism & $1-6$ & $3.07 \downarrow$ & 0.71 & 0.92 & $3.03 \downarrow$ & 0.71 & 0.81 \\
\hline Assertiveness & $1-6$ & $3.80 \uparrow$ & 0.81 & 0.93 & $3.91 \uparrow$ & 0.76 & 0.92 \\
\hline Affiliativeness & $1-6$ & $4.48 \uparrow$ & 0.61 & 0.89 & $4.51 \uparrow$ & 0.59 & 0.88 \\
\hline Depression (BDI-II) & $1-4$ & $1.59 \downarrow$ & 0.54 & 0.94 & - & - & - \\
\hline Depression (CES-D) & $1-4$ & $1.88 \downarrow$ & 0.60 & 0.93 & - & - & - \\
\hline Anxiety (BAl) & $1-4$ & - & - & - & $1.81 \downarrow$ & 0.67 & 0.95 \\
\hline Anxiety (STAI) & $1-4$ & - & - & - & $2.15 \downarrow$ & 0.66 & 0.95 \\
\hline
\end{tabular}

TABLE 3 | Raw and partial correlations between social relations, self-regard, and interpersonal behavior.

\begin{tabular}{|c|c|c|c|c|}
\hline & \multicolumn{2}{|c|}{ Study 1} & \multicolumn{2}{|c|}{ Study 2} \\
\hline & Self-esteem & Narcissism & Self-esteem & Narcissism \\
\hline \multicolumn{5}{|c|}{ Raw correlations } \\
\hline Status & $0.63^{* *}$ & $0.48 * *$ & $0.61^{* *}$ & $0.35^{* *}$ \\
\hline Inclusion & $0.55^{* *}$ & $0.31^{* *}$ & $0.55^{* *}$ & $0.17^{* *}$ \\
\hline \multicolumn{5}{|c|}{ Partial correlations } \\
\hline Status & $0.35^{* *}$ & $0.28^{* *}$ & $0.35^{* *}$ & $0.25^{* *}$ \\
\hline \multirow[t]{2}{*}{ Inclusion } & $0.25^{* *}$ & -0.05 & $0.29 * *$ & $-0.11^{*}$ \\
\hline & Assertiveness & Affiliativeness & Assertiveness & Affiliativeness \\
\hline \multicolumn{5}{|c|}{ Raw correlations } \\
\hline Self-esteem & $0.48^{* *}$ & $0.25^{* *}$ & $0.39 * *$ & $0.21^{* *}$ \\
\hline Narcissism & $0.62^{* *}$ & $-0.17^{* *}$ & $0.50^{* *}$ & $-0.34 * *$ \\
\hline \multicolumn{5}{|c|}{ Partial correlations } \\
\hline Self-esteem & $0.29^{* *}$ & $0.36^{* *}$ & $0.27^{* *}$ & $0.32^{* *}$ \\
\hline Narcissism & $0.50^{* *}$ & $-0.26^{* *}$ & $0.40^{* *}$ & $-0.40^{* *}$ \\
\hline
\end{tabular}

${ }^{*} p<0.01 ; * * p<0.001$

sociometer theory. The findings also support the characterization of narcissism in terms of an agentic surfeit and communal deficit.

\section{Imperative Function: Psychological Self-Regard and Behavioral Strategy}

Both hierometer theory and sociometer theory predict that levels of psychological self-regard will regulate behavioral strategies (i.e., serve an imperative function). The lower panel of Table 3 lists, for both studies, the correlations between the two self-regard variables (i.e., self-esteem and narcissism) and the two behavioral strategy variables (i.e., assertiveness and affiliativeness). Again, these appear in two forms: raw (third row) and partialed (fourth row). The partial correlations between any pair of variables (e.g., narcissism and assertiveness) controlled for overlapping variance attributable to the other pair (e.g., self-esteem and affiliativeness). Here, assertiveness and affiliativeness emerged as largely orthogonal, respective $r s=-0.05$ and $-0.07, p s>0.05$. Nonetheless, for the sake of consistency, we applied the same partialing procedure.

All correlation coefficients were significant. For both raw and partialed correlations, the higher participants' self-esteem, the higher was their assertiveness and affiliativeness; but the higher their narcissism, the higher was their assertiveness and the lower their affiliativeness. Thus, the data were consistent with both forms of self-regard regulating both forms of behavioral strategy, albeit in different ways. They suggest that whereas self-esteem regulates assertiveness and affiliativeness similarly (by making each rise as it rises), narcissism regulates them differently (by making assertiveness rise, but affiliativeness fall, as it rises).

As regards other patterns, the data did not strongly support either form of self-regard being a more potent regulator of behavioral strategies overall, or either form of behavioral strategy being more potently regulated by self-regard overall. The narcissism-assertiveness coefficients were always (absolutely) the highest; the others were closer in magnitude to one another, especially in their partialed 
form. Among the partialed coefficients, a cross-over trend could be discerned, such that self-esteem covaried (slightly) more strongly with affiliativeness than assertiveness, whereas narcissism covaried (much) more strongly with assertiveness than affiliativeness. As before, narcissism seemed to have been characterized by agentic surfeit and a communal deficit.

How then do these findings bear on the validity of the hierometer theory and sociometer theory? As regards hierometer theory, all the findings are fully consistent with it. As both forms of self-regard increased, assertiveness increased; and as both forms of self-regard decreased, assertiveness decreased. These findings suggest a form of adaptive consolidation, with higher or lower levels of self-regard inducing individuals to adopt, respectively, a more assertive or acquiescent behavioral strategy, in keeping with the competitive capacities liable to be conferred by their higher or lower status, and tracked by self-regard. In contrast, dominance theory (Barkow, 1975, 1980) arguably implies the reverse: lower levels of self-regard should have prompted adaptive compensation, inducing individuals to adopt a more assertive behavioral strategy to augment their diminished status. Accordingly, our findings support hierometer theory over dominance theory.

As regards the original version of sociometer theory, the same logic of adaptive compensation versus adaptive consolidation applies, but concerning inclusion and affiliativeness rather than status and assertiveness. Individuals whose self-esteem is lower, due to their lower levels of inclusion, should be more inclined to adopt affiliative behavioral strategies designed to rectify their lower levels of inclusion, whereas those whose self-esteem is higher, due to their higher levels of inclusion, can afford to relax the imperative to affiliate. However, our findings pointed toward the opposite conclusion: levels of self-esteem covaried positively, not negatively, with affiliativeness. This is consistent with a consolidatory rather than a compensatory dynamic. Social exclusion seems to have an alienating impact: it reduces affiliativeness, which is arguably less adaptive in the absence of benevolent and beneficent reciprocators. Such a dynamic would fit with some empirical findings (e.g., Twenge et al., 2007), although not with others (e.g., Maner et al., 2007). Persistent failure to achieve inclusion-which our chronically oriented measures were liable to assess-does seem to promote hostility (DeWall and Richman, 2011).

However, given that narcissism covaried negatively with affiliativeness, it fitted the bill, sociometer-wise, where self-esteem did not. In particular, as narcissism decreased, participants adopted a more affiliative behavioral strategy. This suggests that narcissism might operate in the imperative manner prescribed by the original version of sociometer theory. However, as noted above, narcissism does not operate in the prescribed indicative manner: it also covaried negatively with social inclusion. Hence, narcissism cannot entirely operate as the original version of sociometer theory specifies self-esteem should.

It might be objected that sociometer theory only properly applies to state self-esteem, not to trait self-esteem; and indeed, the bulk of research cited in support of sociometer references state self-esteem (e.g., Leary, 2005). However, associations with trait self-esteem have previously been marshaled in support of sociometer in respect of its prescribed indicative functions (e.g., Leary et al., 1995, 2001; Anthony et al., 2007a; Denissen et al., 2008). This makes it rhetorically difficult to object to their bearing on its prescribed imperative functions also. A case would have to be made for why-if sociometer theory is correct about social inclusion being so essential for survival - individuals who are chronically low in self-esteem, due to chronic social exclusion, should not strive for re-inclusion by adopting a chronically affiliative behavioral strategy.

In all, the patterns obtained were consistent with self-regard serving the imperative functions specified by hierometer theory (for self-esteem and narcissism) but not those specified by sociometer theory (for self-esteem).

\section{Mediational Analyses I: Self-Esteem and Narcissism}

By considering above the separate links between (a) social relations and psychological self-regard, and (b) psychological self-regard and behavioral strategy, we tested, in each case, whether the data were either consistent or inconsistent with self-regard serving the different indicative and imperative functions specified by hierometer theory and (the original version) of sociometer theory. However, both theories additionally specify that the indicative and

TABLE 4 | Raw and partial correlation between social relations and interpersonal behavior.

\begin{tabular}{|c|c|c|c|c|}
\hline & \multicolumn{2}{|c|}{ Study 1} & \multicolumn{2}{|c|}{ Study 2} \\
\hline & Assertiveness & Affiliativeness & Assertiveness & Affiliativeness \\
\hline \multicolumn{5}{|c|}{ Raw correlations } \\
\hline Status & $0.42^{* *}$ & $0.22^{* *}$ & $0.40^{* *}$ & $0.13^{* *}$ \\
\hline Inclusion & $0.35^{* *}$ & $0.35^{* *}$ & $0.31^{* *}$ & $0.31^{* *}$ \\
\hline \multicolumn{5}{|c|}{ Partial correlations } \\
\hline
\end{tabular}

${ }^{* *} p<0.001$. 
imperative functions are coordinated: social relations should affect self-regard, which should in turn affect behavioral strategy. If so, then there should be a link between social relations and behavioral strategy, which is mediated by self-regard.

Table 4 lists, for both studies, all correlations between the two social relations variables (i.e., status and inclusion) and the two behavioral strategy variables (i.e., assertiveness and affiliativeness). These appear in two forms: raw (top row) and doubly partialed (bottom row).

The patterns-especially the raw coefficients-show that, generally speaking, higher status and inclusion covaried positively with assertiveness and affiliativeness. Thus, better social relations generally prompted higher levels of both behavior strategies. Beyond this-as the partialed coefficients best atteststatus covaried relatively more strongly with assertiveness, and inclusion relatively more strongly with affiliativeness.

To test whether self-regard mediated these links, we constructed, for each study, a structural equation model (Kline, 2005). In both sets, we estimated all directional paths using bias-corrected bootstraps on standardized scores (Efron, 1987). As all models were fully saturated, and had zero degrees of freedom, no goodness of fit indices applied (Kline, 2005, p. 133). In the first set of models (Figure 2), we entered status and inclusion as a pair of exogenous predictor variables, self-esteem as an endogenous mediator variable, and assertiveness and affiliativeness as a pair of endogenous outcome variables. We permitted status and inclusion to covary, and we did the same for assertiveness and affiliativeness. In the second set of models (Figure 3), we added narcissism as a second endogenous mediator variable, and additionally permitted self-esteem and narcissism to covary. ${ }^{4,5}$

Across both studies, the findings from the first set of models (Figure 2) were remarkably consistent. Overall, self-esteem significantly and substantially mediated the link between social relations and behavioral strategy. Specifically, the indirect paths between status and assertiveness via self-esteem always attained significance, although the direct paths remained significant too. Likewise, the indirect paths between inclusion and affiliativeness via self-esteem always attained significance, although the direct paths remained significant too. Furthermore, all paths, direct and indirect, were positive in sign, suggesting a consolidatory dynamic, with higher status prompting greater assertiveness by raising self-esteem, and higher inclusion prompting greater affiliativeness in like manner. Finally, the magnitude of the

\footnotetext{
${ }^{4}$ Note that, in principle, many other mediational models could have been considered, some more piecemeal (e.g., involving only hierometer-relevant variables), and others more comprehensive (e.g., involving ancillary variables such as depression and anxiety). However, space limitations regrettably forbade us from considering all of them. We took the defensible view that self-esteem, the canonical form of self-regard invoked by both hierometer theory and sociometer theory, should be tested as the primary mediator of links between social relations and behavioral strategy, and that narcissism, a variant form of self-regard, should be tested as an ancillary mediator.

${ }^{5}$ In the graphical representations of each model, two direct effects and errorcovariances are not displayed for ease of presentation; however, these were included in the statistical models for purposes of estimation.
}

mediation was more marked for the agentic variables invoked by hierometer theory than for the communal variables invoked by (the original version of) sociometer theory. In particular, the path from self-esteem to affiliative behavior was notably weak.

Across both studies, the findings from the second set of models (Figure 3) were also highly consistent. Overall, selfregard-represented by the combination of self-esteem and narcissism-again significantly and substantially mediated the link between social relations and behavioral strategy. However, the pattern of mediation differed markedly for the hierometerrelevant agentic variables and the sociometer-relevant communal variables. This time, the direct path between status and assertiveness dropped to zero in one case, showing that the self-regard "combo" completely mediated the link between status and assertiveness. (The incomplete mediation observed in Study 2 may have been due to its featuring, not the full 40 -item version of the NPI, but rather the abbreviated 16-item version, which sacrificed conceptual coverage for administrative brevity.) Thus, the addition of narcissism to the models, which lowered direct effects from around 0.20 to 0 , substantially augmented the mediation of the statusassertiveness link-again underscoring the value of assessing self-regard in two different ways. In contrast, the addition of narcissism to the model hardly affected the mediation of the inclusion-affiliativeness link: as before, direct effects of around 0.30 emerged. This was primarily because the paths from inclusion to narcissism were near-zero, despite the emergence of strong negative paths between narcissism and affiliativeness, and the positive paths from self-esteem to affiliativeness rising slightly.

This first set of mediational findings fully supports hierometer theory. The data are consistent with self-regard-especially when jointly operationalized as self-esteem and narcissism-acting as a psychological mediator that bridges the gap between status and assertiveness. In particular, they are consistent with selfregard tracking status (by rising or falling in tandem with it) and regulating assertiveness (by making it rise or fall in tandem) to help ensure that individuals navigate adaptively status hierarchies by judiciously engaging in zero-sum contests (i.e., as their status dictates).

Second, the mediational findings only offer at best partial support for the original version of sociometer theory. In the aggregate, the data arguably do not support it. Certainly, our data suggest that self-esteem tracks inclusion, by rising (or falling) in tandem with it. However, they also suggest that, at the same time, self-esteem makes affiliativeness rise (or fall) in tandem with it too. Sociometer theory would arguably predict the opposite, namely, that lower self-esteem should prompt greater affiliativeness, to help restore the fractured bonds of community belongingness, regarded as so fundamental to survival. Yet narcissism did vary inversely with affiliativeness, consistent with one variant form of self-regard regulating behavior in the required direction. At the same time, narcissism hardly covaried with inclusion, thereby ruling it out as a mediator to bridge the sociometer-specified gap between inclusion and affiliativeness. 


\section{HIEROMETER THEORY}

\section{SOCIOMETER THEORY}
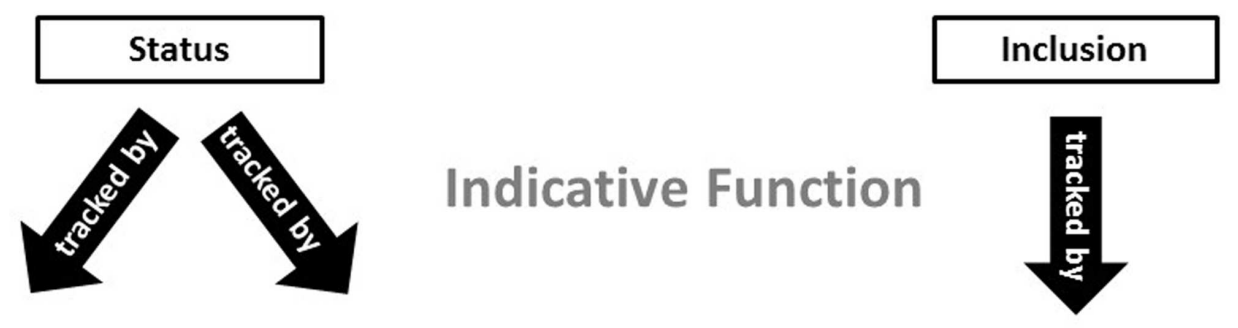

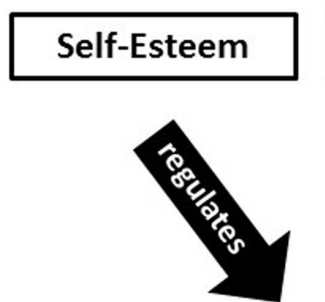

Assertiveness

to match status

\section{Narcissism}

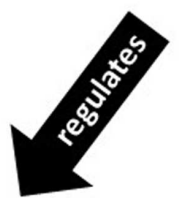

Imperative Function

\section{Self-Esteem}

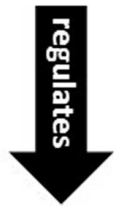

Affiliativeness

to avoid exclusion

\section{Mediational Analyses II: Self-Esteem, Depression, and Anxiety}

Self-esteem is known to covary inversely with most negative emotions, in particular, with anxiety and depression (Baumeister et al., 2003; Sedikides et al., 2004). Furthermore, some theories (Price et al., 1994; Sloman, 2008) state that depression and anxiety evolved to serve indicative and imperative functions similar to those hypothesized by sociometer and hierometer theory to be served by self-esteem. In particular, depression per se has been hypothesized to activate a harm-minimizing "yielding subroutine" (Price and Sloman, 1987) that facilitates the emergence of stable "pecking orders" across speciesrather like hierometer theory proposing that low-esteem curtails assertiveness to optimize competitive performance within social hierarchies. In addition, social anxiety per se has been hypothesized to keep people appropriately mindful of what is socially acceptable lest they fall prey to public sanctionsimilar to sociometer theory proposing that low self-esteem signals to people their levels of social inclusion or relational value are running dangerously low (Gilbert, 2001). Although self-esteem might conceivably operate in concert with anxiety and depression, both hierometer and sociometer theory would be strongly validated if findings emerged that were consistent with self-esteem playing a mediational role independently of anxiety or depression.
Accordingly, to determine whether self-esteem uniquely mediated the link between social relations and behavioral strategy - that is, to test whether the predictions of hierometer theory or sociometer theory held above and beyond the predictions of alternative theories-we ran a further pair of models parallel to the second set above, but replacing narcissism either with depression (assessed in Study 1: Figure 4, top) or anxiety (assessed in Study 2: Figure 4, middle). To facilitate intermodel comparison, we also inverted the depression and anxiety indices, such that higher scores represented lower depression (i.e., cheerfulness) and lower anxiety (i.e., calmness).

Compared to lone mediation by self-esteem (Figure 2), the impact of adding either cheerfulness or calmness to the models, as potential ancillary mediators, differed for the hierometerrelevant agentic variables and the sociometer-relevant communal variables. The path coefficients for status and assertiveness, direct and indirect, hardly changed. The same was true of the path between inclusion and self-esteem. However, the paths between self-esteem and affiliativeness changed substantially: they dropped to non-significance with the addition of either cheerfulness or calmness to the model, ruling out self-esteem serving any unique imperative function. Rather, the data in Study 1 were consistent with cheerfulness independently exhibiting a consolidatory dynamic-with higher inclusion prompting greater affiliativeness by increasing cheerfulness. Such indicative 


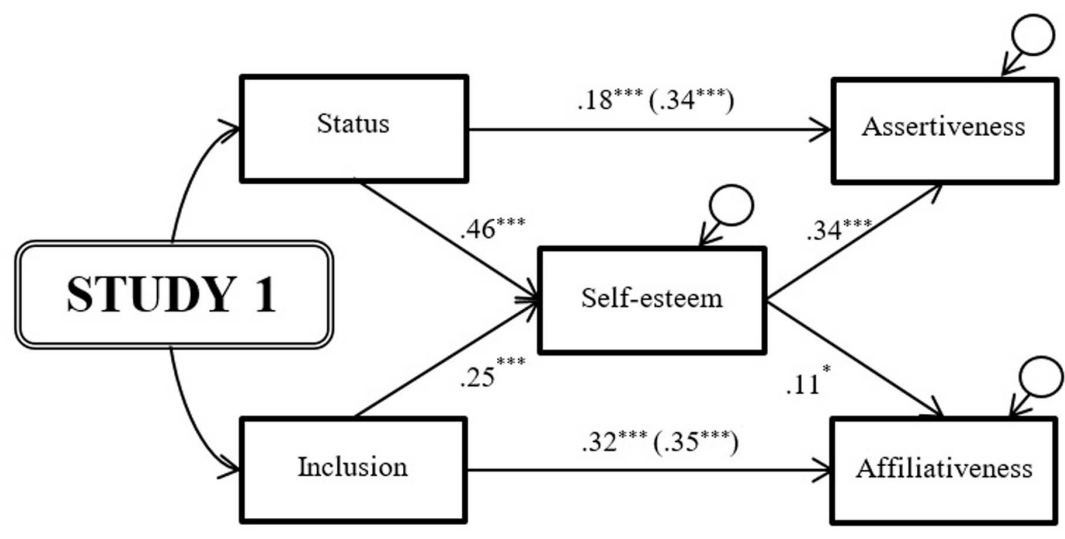

INDIRECT EFFECTS

Status-Assertiveness:

$M_{\text {SELF-ESTEEM }}-\beta=.16^{* * *}$

\section{Inclusion-Affiliativeness:}

$M_{\text {SELF-ESTEEM }}-\beta=.03^{*}$
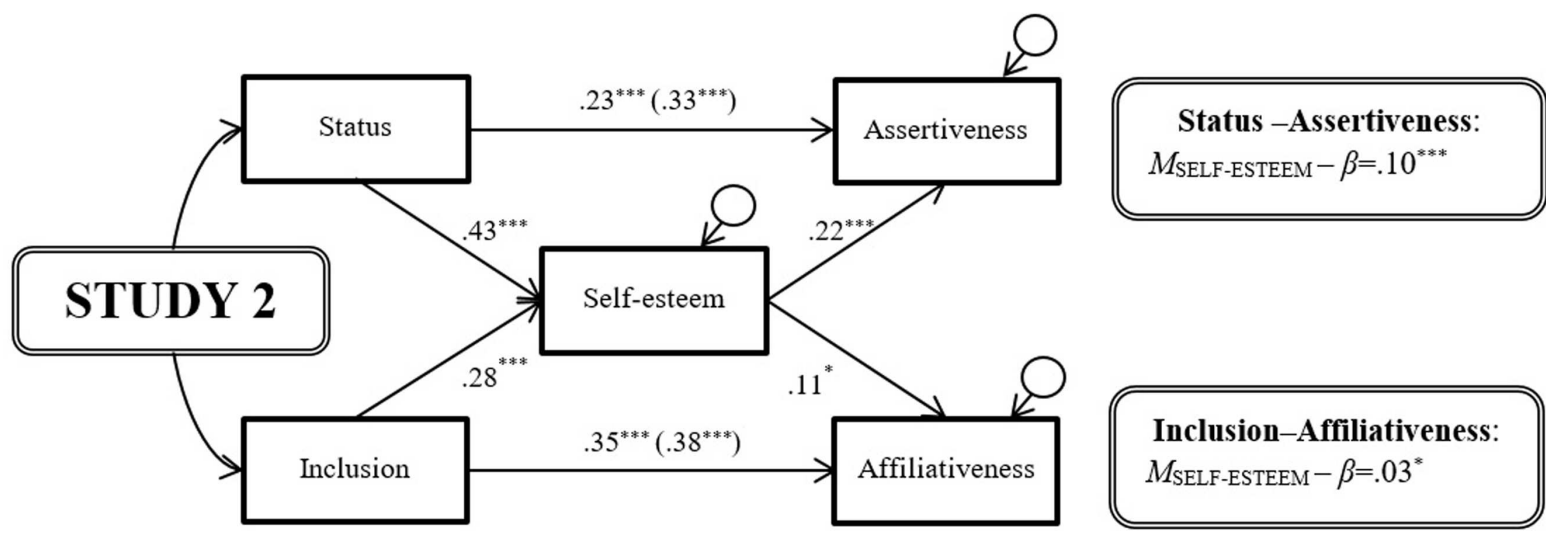

FIGURE 2 | The mediating effect of self-esteem. ${ }^{\dagger} p<0.10 ;{ }^{*} p<0.05 ;{ }^{* *} p<0.01 ;{ }^{* * *} p<0.001$

and imperative functions bear some similarity to those specified by evolutionary theories of clinical disorders (Price et al., 1994). In addition, a positive and significant path emerged between status and cheerfulness, although not between cheerfulness and assertive behavior-only partly in keeping with such theories. In a similar vein, the path coefficients in Study 2 suggestedagain with self-esteem entered simultaneously in the model-that calmness exhibited a consolidatory dynamic like cheerfulness: higher inclusion prompted greater affiliativeness by increasing calmness. However, and again mimicking the pattern for cheerfulness, a positive and significant path emerged between status and calmness, although not between calmness and assertive behavior.

In sum, even when cheerfulness and calmness were included in the models as co-mediators, self-esteem continued to show, in near-unchanged form, the patterns of association with status and assertiveness predicted by hierometer theory. However, although self-esteem also continued to show associations suggestive of tracking inclusion, any associations suggestive of behavioral regulation disappeared. Yet, both cheerfulness (i.e., the inverse of depression) and calmness (i.e., the inverse of anxiety) showed the pattern consistent with the consolidatory dynamic previously shown by self-esteem, in line with evolutionary accounts of their adaptive function.

\section{GENERAL DISCUSSION}

In this article, we put forward, and empirically tested, a novel theory of the evolutionary function of self-regard: hierometer theory. This theory proposes that self-regard operates as part of a system that enables individuals to navigate status hierarchies adaptively. In doing so, individuals must make judicious decisions about whether or not to enter risky zero-sum contests that may not only be beneficially won but also harmfully lost. One factor liable to predict the outcome of such contests is prior social status. Accordingly, hierometer theory proposes that higher (lower) prior social status promotes a behavioral strategy of augmented (diminished) assertiveness, with self-regard acting as the intrapsychic bridge-in particular, tracking social status in the first instance and then regulating behavioral strategy in terms of it. Note that the overall dynamic involved is consolidatory rather than compensatory: higher rather than lower status is proposed to lead to increased assertiveness. In this regard, hierometer theory 


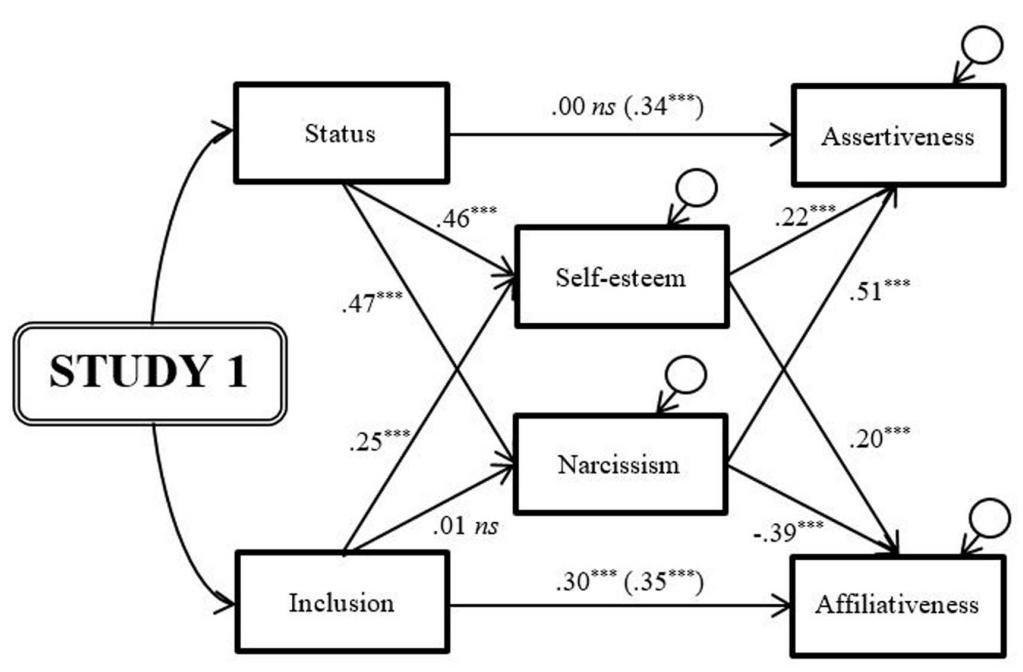

\section{INDIRECT EFFECTS}

\section{Status-Assertiveness:}

$M_{\text {SELF-ESTEEM }}-\beta=.10^{* * *}$

$M_{\text {NARCISSISM }}-\beta=.24^{* * *}$

$M_{\text {AGGREGATE }}-\beta=.34^{* * *}$

Inclusion-Affiliativeness:

$M_{\text {SELF-ESTEEM }}-\beta=.05^{* * 8}$

$M_{\text {NARCISSISM }}-\beta=-.003 n s$

$M_{\text {AGGREGATE }}-\beta=.05^{*}$
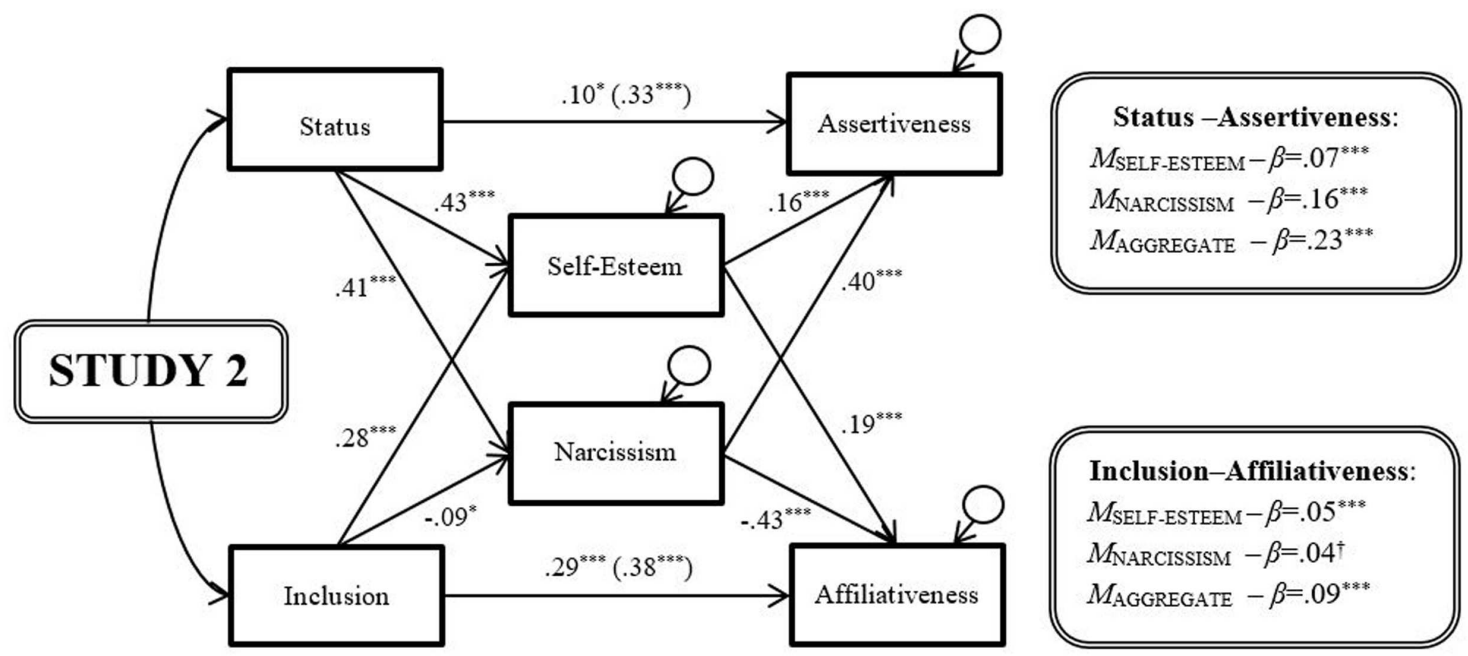

Inclusion-Affiliativeness:

$M_{\text {SELF-ESTEEM }}-\beta=.05^{* * *}$

$M_{\text {NARCISSISM }}-\beta=.04^{\dagger}$

$M_{\text {AGGREGATE }}-\beta=.09^{* * *}$

FIGURE 3 | The mediating effects of self-esteem and narcissism. ${ }^{\dagger} p<0.10 ; * p<0.05 ; * *<0.01 ; * * * p<0.001$.

differs from dominance theory, which arguably implies that it is losses in social status that prompt attempts to regain it (Barkow, 1980).

Hierometer theory also supplements and complements sociometer theory, one leading theory of self-regard's evolutionary function. In its original version, sociometer theory proposes that self-regard-in particular, self-esteem-operates as part of a system that enables people to maintain a minimal level of social acceptance, considered essential to survival. It proposes that self-esteem tracks levels of social acceptance, such that, if social rejection looms, a drop in self-esteem serves as an intrapsychic warning signal, motivating individuals to regain social acceptance by engaging in pro-social (i.e., affiliative) behavior. Note that the dynamic involved is compensatory: Lower rather than higher acceptance is proposed to lead to increased affiliativeness. A revised version of sociometer theory instead proposes that self-esteem tracks relational value more generally; that is, how much one perceives that others value the relationships that one has with them (Leary, 2005).

The explicit formulation of hierometer theory brings out a number of unresolved issues with sociometer theory. The most important of these has to do with the ambiguity over what "social acceptance" means, and by extension, over what "relational value" means.

In particular, individuals can become valued members of society in one of two ways: (a) by being insiders rather than outsiders - that is, by being liked, accepted, and included (Leary et al., 1995); or (b) by being winners rather than losers - that is, by being respected, admired, and deemed important (Magee and Galinsky, 2008). Otherwise put, individuals can achieve social inclusion or social status-two conceptually distinct, if empirically correlated, constructs. The question then arises as to whether and what extent self-regard tracks one versus the otherthe former being more communal in character, and the latter 


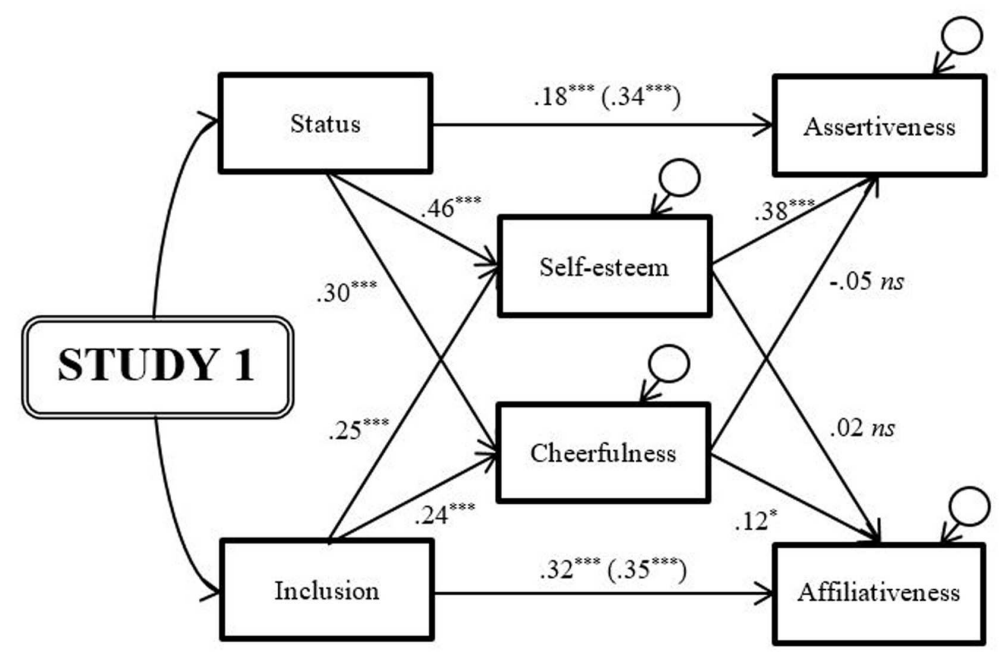

\section{INDIRECT EFFECTS}
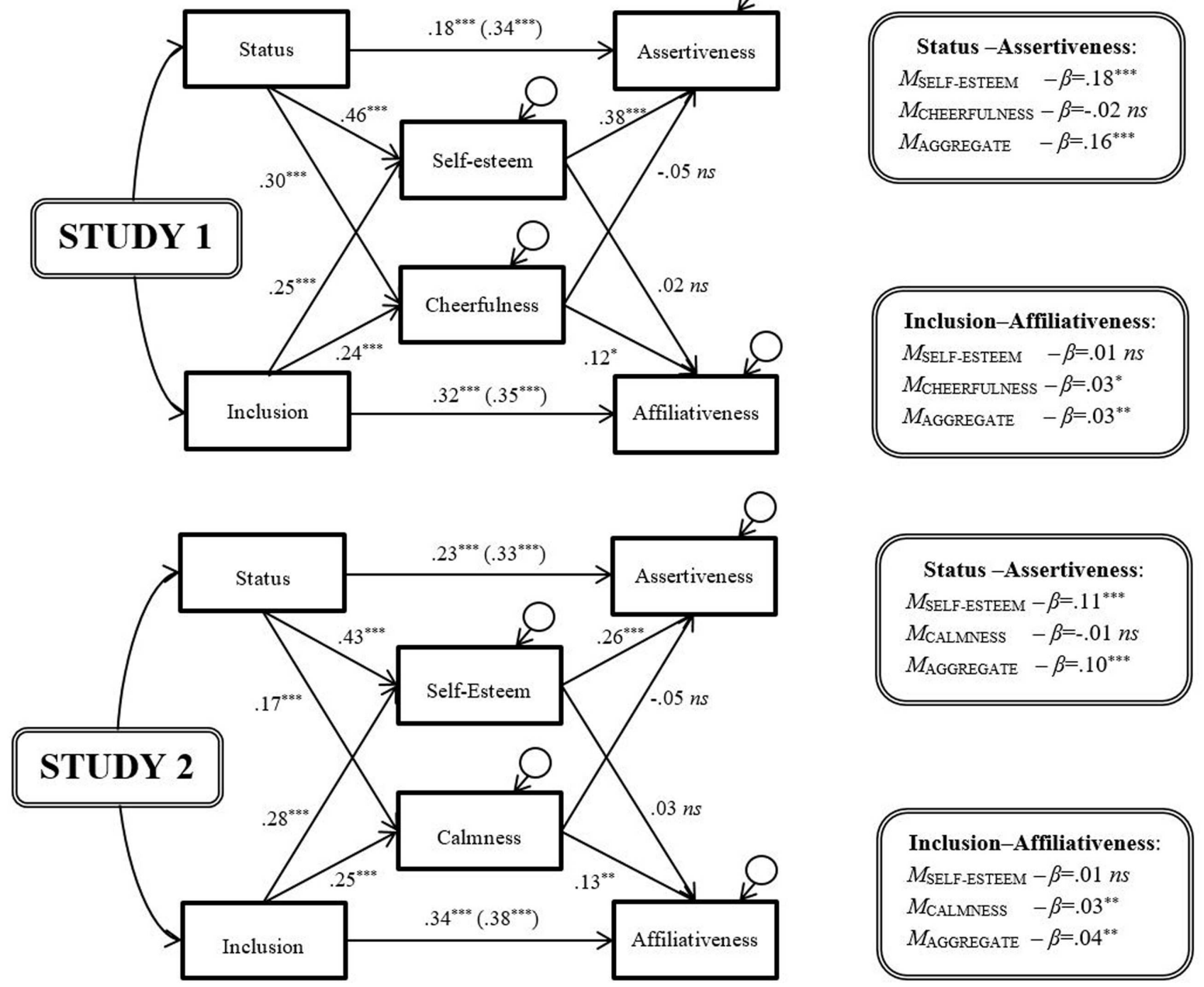

FIGURE 4 | The mediating effects of self-esteem and cheerfulness/calmness. ${ }^{\dagger} p<0.10 ;{ }^{*} p<0.05 ;{ }^{* *} p<0.01 ;{ }^{* * *} p<0.001$.

being more agentic (Bakan, 1966; Huo et al., 2010). Whereas hierometer theory proposes that self-regard tracks status, the original version of sociometer theory proposes that self-regard (self-esteem) tracks inclusion, whereas the revised version leaves the issue open (i.e., tracks any form of relational value). Moreover, both hierometer theory and sociometer theory propose, not only that self-regard tracks social relations, but also that it regulates behavior. Specifically, whereas hierometer theory proposes that self-regard regulates assertive behavior, the original version of sociometer theory proposes that it (self-esteem) regulates affiliative behavior, with the revised version again leaving the issue open (i.e., regulates any behavior relevant to relational value).

Accordingly, by (a) taking the agentic constructs specified by hierometer theory, and the communal constructs specified by the original version of sociometer theory, and by (b) operationalizing them systematically and simultaneously at appropriate levels of analysis (i.e., social, psychological, behavioral), it becomes possible to test, via correlational and mediational means, and controlling for overlapping variance between parallel variables, whether and to what extent self-regard plays the indicative and imperative functions specified by both theories. It also becomes possible to test whether the dynamic involved is either compensatory (such that lower self-regard, evoked by lesser status or inclusion, prompts greater assertiveness or affiliativeness) or consolidatory (such that higher selfregard, evoked by greater status or inclusion, prompts greater assertiveness or affiliativeness). In addition, it is possible to test all the above with respect to two types of self-regard (self-esteem and narcissism), and also controlling for potential confounding variables of a clinical sort (depression and anxiety). In the research reported in this article, we actualized all these possibilities.

At every turn, the predictions of hierometer theory were verified. In both studies, we found that self-regard, whether 
in the form of self-esteem or narcissism, correlated positively with both status and assertiveness-consistent with self-regard tracking the former and regulating the latter. In addition, self-regard statistically mediated the link between status and assertiveness-partially for self-esteem alone, but wholly for selfesteem and narcissism combined, thereby highlighting the value of considering both forms of self-regard jointly, rather than selfesteem alone. The pattern of observed statistical associations suggested that higher (lower) status increases (decreases) selfregard which in turn augments (diminishes) assertiveness. This suggests a consolidatory dynamic: those who have status adopt a riskier behavioral strategy, and those who lack it adopt a safer one, with self-regard acting as the intrapsychic bridge. Furthermore, even when controlling for depression and anxiety-clinical variables also hypothesized to serve an evolutionary role in moderating levels of assertiveness-the correlations consistent with the hypothesized indicative and imperative functions remained robust, thereby raising the likelihood that self-regard indeed acts as the crucial mediator.

Second, the predictions of the original version of sociometer theory were sometimes verified and sometimes falsified, such that, on the whole, the theory was not supported (subject to some caveats below). In particular, self-esteem correlated positively with both inclusion and affiliativeness-consistent with it tracking the former and regulating the latter. Moreover, when considered in isolation, self-esteem also statistically mediated the link between the two. However, the pattern observed suggested that higher (lower) inclusion increases (decreases) self-esteem so as to augment (diminish) affiliativeness. This would imply an indicative function in keeping with the original version of sociometer theory, but an imperative function at odds with it (i.e., decreased self-esteem should augment affiliativeness). Furthermore, when competing clinical variables (i.e., depression and anxiety) were entered into models alongside self-esteem, all links to affiliativeness approached zero, thereby casting doubt on whether self-esteem is an independent mediator of any dynamic, consolidatory or compensatory. Finally, although narcissism did correlate negatively with affiliativeness, it barely correlated with inclusion; hence, as an alternative index of self-regard, narcissism cannot play the role required by self-regard in the original version of sociometer theory either. Note that our findings here are generally in keeping with the accumulated empirical record on sociometer theory to date, which reliably supports the hypothesized indicative function for self-esteem (Leary et al., 1995; Denissen et al., 2008), but only equivocally supports its hypothesized imperative function (Maner et al., 2007; Twenge et al., 2007).

That our findings for self-esteem were consistent with hierometer theory, but not or not entirely with the original version of sociometer theory, further suggests that, although self-esteem is both agency-based and communion-based, it is relatively more agency-based than communion-based-a conclusion also reached independently by other researchers (Wojciszke et al., 2011). Indeed, in this connection, Gebauer et al. (2015) recently found, in two very large cross-cultural studies, featuring self-reports and informant reports respectively, that the Big Five personality trait of extraversion-the one most related to agency and "getting-ahead"- uniquely predicted selfesteem, whereas the trait of agreeableness-the one most related to communion and "getting along"-did not. In addition, and as expected, narcissism emerged as relatively more agency-based than communion-based (Sedikides et al., 2002; cf. Campbell and Foster, 2007), in that it entailed a deficit in communion for some links (e.g., to affiliativeness) and a surfeit in agency for others (e.g., to assertiveness). Nonetheless, some links (e.g., to status) were equally strong for self-esteem and narcissism.

We believe that the foregoing discussion illustrates how our correlational and mediational findings-by being either in keeping, or at odds, with different theoretically derived predictions-serve either to provide support for, or to call into question, the theories that yield those predictions, thereby moving forward the investigation of the function of self-regard. That is, even if correlation and mediation do not prove causation, causal theories can nonetheless be tested by whether or not observed patterns of correlation and mediation are consistent with their predictions. In other words, although consistent patterns do not decisively establish a theory, inconsistent patterns do have the power to undermine it. As one of the progenitors of sociometer theory has emphasized "[absent] measurement error or methodological shortcomings ... null correlations falsify causal hypotheses (Baumeister et al., 2003, p. 9).” For example, in the current research, a failure to find a unique positive correlation between status and self-esteem, after controlling for both inclusion and narcissism, would have called hierometer theory into question, and unequivocally supported the original version of sociometer theory, which emphasizes inclusion. Especially as a first step toward validating a promising theory, such correlational and mediational patterns are, at the very least, informative. In any case, complementary experimental research is now underway that has begun to establish the causal links specified by hierometer theory (Mahadevan et al., 2015).

In defense of sociometer theory, however, at least two caveats merit consideration. First, we focused on long-standing conditions, at a social, psychological, or behavioral level. Accordingly, we assessed all our variables in either chronic or trait form. Had we instead focused on changing conditions, and so assessed our variables in either acute or state form, more evidence of a compensatory dynamic might have come to light. Specifically, in line with the original version of sociometer theory, acute drops in state self-esteem might have momentarily augmented affiliativeness (Maner et al., 2007). Similarly, in line with dominance theory, acute drops in self-regard might have momentarily augmented assertiveness (Barkow, 1980). Ultimately, the timespan over which relevant variables are measured may be a critical moderator of, and a limiting condition on, the applicability of hierometer and sociometer theory. Nonetheless, given that links between constructs assessed at a chronic and trait level have been previously adduced as evidence for sociometer theory (Leary et al., 1995, 2001; Anthony et al., 2007a; Denissen et al., 2008), it is legitimate that they be adduced as evidence for hierometer theory, especially given its novelty. To count such chronic links as evidence for sociometer theory, but not for hierometer theory, would be tantamount to discrimination. 
Second, our findings are arguably consistent with the revised version of sociometer theory, which is equivocal about the type of relational value that self-esteem tracks, and by extension, the type of social acceptance that goes hand in hand with it. Indeed, hierometer theory, and the original version of sociometer theory, might each be considered complementary subsets of the revised version of sociometer theory, if the latter is construed very broadly as a theory which states that types of social relations (status, inclusion), which constitute different types of relational value, regulate types of behavioral strategies (assertiveness, affiliativeness) via types of self-regard (self-esteem, narcissism). If so, then our confirmatory findings for hierometer theory, and mixed findings for the original version of sociometer theory, would still suggest that the revised version of sociometer theory holds truer for agentic variables than for communal ones.

\section{CONCLUSION}

It matters whether, in the social world, one is either a winner or a loser, or an insider or outsider. Both outcomes seem to

\section{REFERENCES}

Ackerman, R. A., Witt, E. A., Donnellan, M. B., Trzesniewski, K. H., Robins, R. W., and Kashy, D. A. (2011). What does the narcissistic personality inventory really measure? Assessment 18, 67-87. doi: 10.1177/10731911103 82845

Ames, D., Rose, P., and Anderson, C. (2006). The NPI-16 as a short measure of narcissism. J. Res. Pers. 40, 440-449. doi: 10.1016/j.jrp.2005. 03.002

Anderson, C., Hildreth, J. A. D., and Howland, L. (2015). Is the desire for status a fundamental human motive? A review of the empirical literature. Psychol. Bull. 141, 574-601. doi: 10.1037/a0038781

Anderson, C., John, O. P., Keltner, D., and Kring, A. L. (2001). Who attains social status? Effects of personality traits and physical attractiveness in social groups. J. Pers. Soc. Psychol. 81, 116-132. doi: 10.1037/0022-3514.81.1.116

Anderson, C., Srivastava, S., Beer, J. S., Spataro, S. E., and Chatman, J. A. (2006). Knowing your place: self-perceptions of status in face-to-face groups. J. Pers. Soc. Psychol. 91, 1094-1110. doi: 10.1037/0022-3514.91.6.1094

Anthony, D. B., Holmes, J. G., and Wood, J. V. (2007a). Social acceptance and selfesteem: tuning the sociometer to interpersonal value. J. Pers. Soc. Psychol. 92, 1024-1039. doi: 10.1037/0022-3514.92.6.1024

Anthony, D. B., Wood, J. V., and Holmes, J. G. (2007b). Testing sociometer theory: self-esteem and the importance of acceptance for social decision-making. J. Exp. Soc. Psychol. 43, 425-432. doi: 10.1016/j.jesp.2006.03.002

Back, M. D., Krause, S., Hirschmüller, S., Stopfer, J. M., Egloff, B., and Schmukle, S. C. (2009). Unraveling the three faces of self-esteem: a new information-processing sociometer perspective. J. Res. Pers. 43, 933-937. doi: 10.1016/j.jrp.2009.04.002

Bakan, D. (1966). The Duality of Human Existence: Isolation and Communion in Western Man. Boston, MA: Beacon Press.

Barkow, J. H. (1975). "Prestige and culture: a biosocial interpretation," in Current Anthropology, Vol. 16, ed. M. Aldenderfer (Chicago, IL: University of Chicago Press), 553-572.

Barkow, J. H. (1980). "Prestige and self-esteem: a biosocial interpretation," in Dominance Relations: An Ethological View of Human Conflict and Social Interaction, eds D. R. Omark, F. F. Strayer, and D. G. Freedman (New York, NY: Garland SMTP Press), 319-332.

Baumeister, R. F., Campbell, J. D., Krueger, J. I., and Vohs, K. D. (2003). Does high self-esteem cause better performance, interpersonal success, happiness, or healthier lifestyles? Psychol. Sci. Public Interest 4, 1-44. doi: 10.1111/15291006.01431 independently shape how individuals feel about themselves, and in turn, how they behave. But the pattern of data we obtained is most consistent with the outcome of being a winner or loser ultimately regulating how assertively or acquiescently individuals behave. In particular, prompted by their levels self-regardpeople on an already winning trajectory seem motivated to seek further wins, whereas those on a losing trajectory seem motivated to avoid further losses. Such a dynamic system, which serves to consolidate individuals' existing statuses, arguably helps them prudently navigate social hierarchies, by optimizing their judicious participation in risky zero-sum contests.

\section{AUTHOR CONTRIBUTIONS}

The theory was developed by NM and AG, with input from CS and WDW-A. NM and AG developed the studies and NM collected the data. Data were analysed by NM (primary) and AG (secondary). NM and AG co-wrote the manuscript which was then further refined by CS, WDW-A, NM, and AG.

Baumeister, R. F., and Leary, M. R. (1995). The need to belong: desire for interpersonal attachments as a fundamental human motivation. Psychol. Bull. 117, 497-529. doi: 10.1037/0033-2909.117.3.497

Beck, A. T., Epstein, N., Brown, G., and Steer, R. A. (1988). An inventory for measuring clinical anxiety: psychometric properties. J. Consult. Clin. Psychol. 56, 893-897. doi: 10.1037/0022-006X.56.6.893

Beck, A. T., Steer, R. A., and Brown, G. K. (1996). Manual for Beck Depression Inventory-II. San Antonio, TX: Psychological Corporation.

Bernstein, M. J., Claypool, H. M., Young, S. G., Tuscherer, T., Sacco, D. F., and Brown, C. M. (2013). Never let them see you cry: self-presentation as a moderator of the relationship between exclusion and self-esteem. Pers. Soc. Psychol. Bull. 39, 1293-1305. doi: 10.1177/0146167213495281

Betzig, L. (1986). Despotism and Differential Reproduction. New York NY: Aldine.

Blackhart, G. C., Nelson, B. C., Knowles, M. L., and Baumeister, R. F. (2009). Rejection elicits emotional reactions but neither causes immediate distress nor lowers self-esteem: a meta-analytic review of 192 studies on social exclusion. Pers. Soc. Psychol. Rev. 13, 269-309. doi: 10.1177/1088868309346065

Bourgeois, K. S., and Leary, M. R. (2001). Coping with rejection: derogating those who choose us last. Motiv. Emot. 25, 101-111. doi: 10.1023/A:1010661 825137

Brunell, A. B., and Campbell, W. K. (2011). "Narcissism and romantic relationships," in Handbook of Narcissism and Narcissistic Personality Disorder, eds W. K. Campbell and J. D. Miller (Hoboken, NJ: Wiley), 344-350.

Buckley, K. E., Winkel, R. E., and Leary, M. R. (2004). Reactions to acceptance and rejection: effects of level and sequence of relational evaluation. J. Exp. Soc. Psychol. 40, 14-28. doi: 10.1016/S0022-1031(03)00064-7

Buhrmester, M., Kwang, T., and Gosling, S. D. (2011). Amazon's Mechanical Turk a new source of inexpensive, yet high-quality, data? Perspect. Psychol. Sci. 6, 3-5. doi: 10.1177/1745691610393980

Byrne, B. M. (1996). Measuring Self-Concept Across the Life Span: Methodological Issues and Selected Instrumentation. Washington, DC: American Psychological Association.

Campbell, W. K. (1999). Narcissism and romantic attraction. J. Pers. Soc. Psychol. 77, 1254-1270. doi: 10.1037/0022-3514.77.6.1254

Campbell, W. K., and Foster, J. D. (2007). "The narcissistic self: background, an extended agency model, and ongoing controversies," in Frontiers in Social Psychology: The Self, eds C. Sedikides and S. Spencer (Philadelphia, PA: Psychology Press), 115-138.

Campbell, W. K., and Miller, J. D. (2011). The Handbook of Narcissism and Narcissistic Personality Disorder: Theoretical Approaches, Empirical findings, and Treatments. Hoboken, NJ: John Wiley \& Sons. 
Campbell, W. K., Rudich, E., and Sedikides, C. (2002). Narcissism, self-esteem, and the positivity of self-views: two portraits of self-love. Pers. Soc. Psychol. Bull. 28, 358-368. doi: 10.1177/0146167202286007

Crocker, J., Karpinski, A., Quinn, D. M., and Chase, S. K. (2003). When grades determine self-worth: consequences of contingent self-worth for male and female engineering and psychology majors. J. Pers. Soc. Psychol. 85, 507-516. doi: 10.1037/0022-3514.85.3.507

Crocker, J., Sommers, S. R., and Luhtanen, R. K. (2002). Hopes dashed and dreams fulfilled: contingencies of self-worth and graduate school admissions. Pers. Soc. Psychol. Bull. 28, 1275-1286. doi: 10.1177/01461672022812012

Cuddy, A. J., Fiske, S. T., and Glick, P. (2008). Warmth and competence as universal dimensions of social perception: the stereotype content model and the BIAS map. Adv. Exp. Soc. Psychol. 40, 61-149. doi: 10.1016/S0065-2601(07) 00002-0

Deci, E. L., and Ryan, R. M. (2000). The "what" and "why" of goal pursuits: human needs and the self-determination of behavior. Psychol. Inquiry 11, 227-268. doi: 10.1207/S15327965PLI1104_01

Denissen, J. J. A., Penke, L., Schmitt, D. P., and van Aken, M. A. G. (2008). Selfesteem reactions to social interactions: evidence for sociometer mechanisms across days, people, and nations. J. Pers. Soc. Psychol. 95, 181-196. doi: 10.1037/0022-3514.95.1.181

DeWall, C. N., and Richman, S. B. (2011). Social exclusion and the desire to reconnect. Soc. Pers. Psychol. Compass 5, 919-932. doi: 10.1111/j.17519004.2011.00383.x

Efron, B. (1987). Better bootstrap confidence intervals. J. Am. Stat. Assoc. 82, 171-200. doi: 10.1080/01621459.1987.10478410

Fiske, S. T. (2010). "Interpersonal stratification: status, power, and subordination," in Handbook of Social Psychology, 5th Edn, eds S. T. Fiske, D. T. Gilbert, and G. Lindzey (New York, NY: Wiley), 941-982.

Foa, U. G. (1961). Convergences in the analysis of the structure of interpersonal behavior. Psychol. Rev. 68, 341-353. doi: 10.1037/h0039638

Frank, R. H. (1985). Choosing the Right Pond: Human Behavior and the Quest for Status. New York, NY: Oxford University Press.

Gebauer, J. E., Sedikides, C., Wagner, J., Bleidorn, W., Rentfrow, P. J., Potter, J., et al. (2015). Cultural norm fulfillment, interpersonal belonging, or gettingahead? A large-scale cross-cultural test of three perspectives on the function of self-esteem. J. Pers. Soc. Psychol. 109, 526-548. doi: 10.1037/pspp00 00052

Gebauer, J. E., Wagner, J., Sedikides, C., and Neberich, W. (2013). The relation between agency-communion and self-esteem is moderated by culture, religiosity, age, and sex: evidence for the self-centrality breeds selfenhancement principle. J. Pers. 81, 261-275. doi: 10.1111/j.1467-6494.2012. 00807.x

Germine, L., Nakayama, K., Duchaine, B., Chabris, C., Chatterjee, G., and Wilmer, J. (2012). Is the web as good as the lab? Comparable performance from web and lab in cognitive/perceptual experiments. Psychon. Bull. Rev. 19, 847-857. doi: 10.3758/s13423-012-0296-9

Gilbert, P. (2000). The relationship of shame, social anxiety and depression: the role of evaluation of social rank. Clin. Psychol. Psychother. 7, 174-189. doi: 10.1002/1099-0879

Gilbert, P. (2001). Evolution and social anxiety. The role of attraction, social competition, and social hierarchies. Psychiatr. Clin. North Am. 24, 723-751. doi: 10.1016/S0193-953X(05)70260-4

Gilbert, P., Price, J., and Allan, S. (1995). Social comparison, social attractiveness, and evolution: how might they be related? New Ideas Psychol. 13, 149-165. doi: 10.1016/0732-118X(95)00002-X

Gregg, A. P., Sedikides, C., and Gebauer, J. E. (2011). "Dynamics of identity: between self-enhancement and self-assessment," in Handbook of Identity Theory and Research, Vol. 1, eds S. J. Schwartz, K. Luyckx, and V. L. Vignoles (New York, NY: Springer), 305-327.

Haupt, A. L., and Leary, M. R. (1997). The appeal of worthless groups: moderating effects of trait self-esteem. Group Dyn. 1, 124-132. doi: 10.1037/10892699.1.2.124

Holtzman, N. S., and Strube, M. J. (2011). "The intertwined evolution of narcissism and short-term mating: an emerging hypothesis," in The Handbook of Narcissism and Narcissistic Personality Disorder: Theoretical Approaches, Empirical Findings, and Treatments, eds W. K. Campbell and J. D. Miller (Hoboken, NJ: Wiley), 210-220.
Huo, Y. J., Binning, K. R., and Molina, L. E. (2010). Testing an integrative model of respect: implications for social engagement and well-being. Pers. Soc. Psychol. Bull. 36, 200-212. doi: 10.1177/0146167209356787

Josephs, R. A., Larrick, R. P., Steele, C. M., and Nisbett, R. E. (1992). Protecting the self from the negative consequences of risky decisions. J. Pers. Soc. Psychol. 62, 26-37. doi: 10.1037/0022-3514.62.1.26

Kernis, M. H. (2003). Toward a conceptualization of optimal self-esteem. Psychol. Inquiry 14, 1-26. doi: 10.1207/S15327965PLI1401_01

Kirkpatrick, L. A., and Ellis, B. J. (2001). "An evolutionary-psychological approach to self-esteem: multiple domains and multiple functions," in The Blackwell Handbook of Social Psychology, Vol. 2, eds G. Fletcher and M. Clark (Oxford: Blackwell), 411-436.

Klein, P. G. (2010). The Capitalist and the Entrepreneur: Essays on Organizations and Markets. Auburn, AL: Ludwig von Mises Institute.

Kline, R. B. (2005). Principles and Practice of Structural Equation Modelling, 2nd Edn. New York, NY: Guilford Press.

Koch, E. J., and Shepperd, J. A. (2008). Testing competence and acceptance explanations of self-esteem. Self Identity 7, 54-74. doi: $10.1080 / 15298860601005826$

Landau, M. J., and Greenberg, J. (2006). Play it safe or go for the gold? A terror management perspective on self-enhancement and protection motives in risky decision making. Pers. Soc. Psychol. Bull. 32, 1633-1645. doi: $10.1177 / 0146167206292017$

Leary, M. R. (1999). Making sense of self-esteem. Curr. Dir. Psychol. Sci. 8, 32-35. doi: $10.1111 / 1467-8721.00008$

Leary, M. R. (2004). "The sociometer, self-esteem, and the regulation of interpersonal behavior," in Handbook of Self-Regulation, eds R. F. Baumeister and K. D. Vohs (New York, NY: Guilford).

Leary, M. R. (2005). Sociometer theory and the pursuit of relational value: getting to the root of self-esteem. Eur. Rev. Soc. Psychol. 16, 75-111. doi: $10.1080 / 10463280540000007$

Leary, M. R., and Baumeister, R. F. (2000). "The nature and function of self-esteem: sociometer theory," in Advances in Experimental Social Psychology, Vol. 32, ed. M. P. Zanna (San Diego: Academic Press), 1-62.

Leary, M. R., Cottrell, C. A., and Phillips, M. (2001). Deconfounding the effects of dominance and social acceptance on self-esteem. J. Pers. Soc. Psychol. 81, 898-909. doi: 10.1037/0022-3514.81.5.898

Leary, M. R., and Downs, D. L. (1995). "Interpersonal functions of the selfesteem motive: the self-esteem system as a sociometer," in Efficacy, Agency, and Self-Esteem, ed. M. H. Kernis (New York, NY: Plenum), 123-144.

Leary, M. R., Haupt, A., Strausser, K., and Chokel, J. (1998). Calibrating the sociometer: the relationship between interpersonal appraisals and state self-esteem. J. Pers. Soc. Psychol. 74, 1290-1299. doi: 10.1037/0022-3514.74. 5.1290

Leary, M. R., Tambor, E. S., Terdal, S. J., and Downs, D. L. (1995). Self-esteem as an interpersonal monitor. The sociometer hypothesis. J. Pers. Soc. Psychol. 68, 518-530. doi: 10.1037/0022-3514.68.3.518

Lee, S., Gregg, A. P., and Park, S. H. (2013). The person in the purchase: narcissistic consumers prefer products that positively distinguish them. J. Pers. Soc. Psychol. 105, 335-352. doi: 10.1037/a0032703

MacDonald, G., Saltzman, J. L., and Leary, M. R. (2003). Social approval and trait self-esteem. J. Res. Pers. 37, 23-40. doi: 10.1016/S0092-6566(02)00531-7

Magee, J. C., and Galinsky, A. D. (2008). Social hierarchy: the self-reinforcing nature of power and status. Acad. Manage. Ann. 2, 351-398. doi: $10.1080 / 19416520802211628$

Mahadevan, N., Gregg, A. P., and Sedikides, C. (2015). Not all Social Relations are Created Equal: The Differential Effects of Status and Inclusion on Self-Regard and their Implications. Southampton: University of Southampton.

Maner, J. K., DeWall, N., Baumeister, R. F., and Schaller, M. (2007). Does social exclusion motivate interpersonal reconnection? Resolving the “porcupine problem.” J. Pers. Soc. Psychol. 92, 42-55. doi: 10.1037/0022-3514. 92.1.42

Marmot, M. (2004). The Status Syndrome: How your Social Standing Affects your Health and Life Expectancy. London: Bloomsbury.

Maynard Smith, J. (1982). Evolution and the Theory of Games. Cambridge: Cambridge University Press.

Mazur, A. (1985). A biosocial model of status in face-to-face primate groups. Soc. Forces 64, 377-402. doi: 10.1093/sf/64.2.377 
McCrae, R. R., and Costa, P. T. Jr. (1989). The structure of interpersonal traits: wiggins's circumplex and the five-factor model. J. Pers. Soc. Psychol. 56, 586-595. doi: 10.1037/0022-3514.56.4.586

Mead, N. L., Baumeister, R. F., Stillman, T. F., Rawn, C. D., and Vohs, K. D. (2011). Social exclusion causes people to spend and consume strategically in the service of affiliation. J. Consumer Res. 37, 902-919. doi: 10.1086/656667

Metzinger, T. (2003). Being No One: The Self-Model Theory of Subjectivity. Cambridge, MA: MIT Press.

Miller, J. D., McCain, J., Lynam, D. R., Few, L. R., Gentile, B., MacKillop, J., et al. (2014). A comparison of the criterion validity of popular measures of narcissism and Narcissistic Personality Disorder via the use of expert ratings. Psychol. Assess. 26, 958-969. doi: 10.1037/a0036613

Morf, C. C., Horvath, S., and Torchetti, L. (2011). "Narcissistic self- enhancement: Tales of successful? self-portrayal," in Handbook of Self-Enhancement and SelfProtection, eds M. D. Alicke and C. Sedikides (New York, NY: Guilford), 399-424.

Morse, S. and Gergen, K. J. (1970). Social comparison, self-consistency, and the concept of self. J. Pers. Soc. Psychol. 16, 148-156.

Moskowitz, D. S. (1994). Cross-situational generality and the interpersonal circumplex. J. Pers. Soc. Psychol. 66, 921-933. doi: 10.1037/0022-3514.66.5.921

Nowak, M. A., and Highfield, R. (2011). Supercooperators: Why We Need each other to Succeed. New York, NY: Simon \& Schuster.

Paulhus, D. L., Robins, R. W., Trzesniewski, K. H., and Tracy, J. L. (2004). Two replicable suppressor situations in personality research. Multiv. Behav. Res. 39, 303-328. doi: 10.1207/s15327906mbr3902_7

Pincus, A. L., Ansell, E. B., Pimentel, C. A., Cain, N. M., Wright, A. G. C., and Levy, K. N. (2009). Initial construction and validation of the pathological narcissism inventory. Psychol. Assess. 21, 365-379. doi: 10.1037/a0016530

Price, J. S., and Sloman, L. (1987). Depression as yielding behavior: an animal model based on Schjelderup-Ebbe's pecking order. Ethol. Sociobiol. 8, 85S-98S. doi: 10.1016/0162-3095(87)90021-5

Price, J. S., Sloman, L., Gilbert, P., Gardner, R., and Rohde, P. (1994). The social competition hypothesis of depression. Br. J. Psychiatry 164, 309-315. doi: 10.1192/bjp.164.3.309

Pyszczynski, T., Greenberg, J., Solomon, S., Arndt, J., and Schimel, J. (2004). Why do people need self-esteem? A theoretical and empirical review. Psychol. Bull. 130, 435-468. doi: 10.1037/0033-2909.130.3.435

Radloff, L. S. (1977). The CES-D Scale: a self-report depression scale for research in the general population. Appl. Psychol. Measur. 1, 385-401. doi: $10.1177 / 014662167700100306$

Raskin, R., and Hall, C. S. (1981). The Narcissistic personality inventory: alternate form reliability and further evidence of construct validity. J. Pers. Assess. 45, 159-162. doi: 10.1207/s15327752jpa4502_10

Rhodewalt, F., and Peterson, B. (2009). "Narcissism," in Handbook of Individual Differences in Social Behavior, eds M. R. Leary and R. H. Hoyle (New York, NY: The Guilford Press), 547-560.

Ridgeway, C. L., and Berger, J. (1986). Expectations, legitimation, and dominance behavior in task groups. Am. Sociol. Rev. 51, 603-617. doi: 10.2307/2095487

Rosenberg, M. (1965). Society and the Adolescent Self-image. Princeton, NJ: Princeton University Press.

Sapolsky, R. M. (2005). The influence of social hierarchy on primate health. Science 308, 648-652. doi: 10.1126/science.1106477

Schlitz, D. A. (1978). The Gambler [Recorded by Kenny Rogers]. On The Gambler [Vinyl]. Los Angeles, CA: United Artists.

Sedikides, C., Campbell, W. K., Reeder, G. D., Elliot, A. J., and Gregg, A. P. (2002). "Do others bring out the worst in narcissists? The "others exist for me" illusion," in Self and Identity: Personal, Social, and Symbolic, eds Y. Kashima and M. Foddy (Mahwah, NJ: Erlbaum), 103-124.

Sedikides, C., and Gregg, A. P. (2008). Self-enhancement: food for thought. Perspect. Psychol. Sci. 3, 102-116. doi: 10.1111/j.1745-6916.2008.00068.x

Sedikides, C., Rudich, E. A., Gregg, A. P., Kumashiro, M., and Rusbult, C. (2004). Are normal narcissists psychologically healthy? Self-esteem matters. J. Pers. Soc. Psychol. 87, 400-416. doi: 10.1037/0022-3514.87.3.400

Sidanius, J., and Pratto, F. (1999). Social Dominance: An Intergroup Theory of Social Hierarchy and Oppression. Cambridge: Cambridge University Press.

Sklansky, D. (1994). The Theory of Poker. Las Vegas: Two Plus Two Publishing.

Sloman, L. (2008). A new comprehensive evolutionary model of depression and anxiety. J. Affect. Disord. 106, 219-228. doi: 10.1016/j.jad.2007.07.008
Sloman, L., and Price, J. (1987). Losing behaviour (yielding subroutine) and human depression: proximate and selective mechanisms. Ethol. Sociobiol. 8, 99-109. doi: 10.1016/0162-3095(87)90022-7

Spielberger, C. D., Gorsuch, R. L., Lushene, R., Vagg, P. R., and Jacobs, G. A. (1983). State-Trait Anxiety Inventory for Adults. Palo Alto, CA: Consulting Psychologists Press.

Twenge, J. M., Baumeister, R. F., DeWall, C. N., Ciarocco, N. J., and Bartels, J. M. (2007). Social exclusion decreases prosocial behavior. J. Pers. Soc. Psychol. 92, 56-66. doi: 10.1037/0022-3514.92.1.56

Twenge, J. M., Baumeister, R. F., Tice, D. M., and Stucke, T. S. (2001). If you can't join them, beat them: effects of social exclusion on aggressive behavior. J. Pers. Soc. Psychol. 81, 1058-1069. doi: 10.1037/0022-3514.81. 6.1058

Twenge, J. M., and Campbell, W. K. (2002). Self-esteem and socioeconomic status: a meta-analytic review. Pers. Soc. Psychol. Rev. 6, 59-71. doi: 10.1207/S15327957PSPR0601_3

Twenge, J. M., Konrath, S., Foster, J. D., Keith Campbell, W., and Bushman, B. J. (2008). Egos inflating over time: a cross-temporal meta-analysis of the Narcissistic Personality Inventory. J. Pers. 76, 875-902. doi: 10.1111/j.14676494.2008.00507.x

von Mises, L. (1963). Human Action. Chicago, IL: Contemporary Books Inc.

von Rueden, C., Gurven, M., and Kaplan, H. (2008). Multiple dimensions of male social status in an Amazonian society. Evol. Hum. Behav. 29, 402-415. doi: 10.1016/j.evolhumbehav.2008.05.001

von Rueden, C., Gurven, M., and Kaplan, H. (2011). Why do men seek status? Fitness payoffs to dominance and prestige. Proc. R. Soc. B Biol. Sci. 278, 2223-2232. doi: 10.1098/rspb.2010.2145

Wiggins, J. S. (1979). A psychological taxonomy of trait-descriptive terms: the interpersonal domain. J. Pers. Soc. Psychol. 37, 395-412. doi: 10.1037/00223514.37.3.395

Williams, K. D., Cheung, C. K. T., and Choi, W. (2000). Cyberostracism: effects of being ignored over the internet. J. Pers. Soc. Psychol. 79, 748-762. doi: 10.1037/0022-3514.79.5.748

Wilson, E. O. (2012). The Social Conquest of Earth. New York, NY: Liveright Publishing Corporation.

Wojciszke, B., Baryla, W., Parzuchowski, M., Szymkow, A., and Abele, A. E. (2011). Self-esteem is dominated by agentic over communal information. Eur. J. Soc. Psychol. 40, 1-11. doi: 10.1002/ejsp.791

Wojciszke, B., and Struzynska-Kujalowicz, A. (2007). Power influences self-esteem. Soc. Cogn. 25, 510-532. doi: 10.1521/soco.2007.25.4.472

Wrangham, R. W., and Wilson, M. L. (2004). Collective violence: comparisons between youths and chimpanzees. Ann. N. Y. Acad. Sci. 1036, 1-25. doi: 10.1196/annals. 1330.015

Wray, L. D., and Stone, E. R. (2005). The role of self-esteem and anxiety in decision making for self versus others in relationships. J. Behav. Decis. Mak. 18, 125-144. doi: 10.1002/bdm.490

Zadro, L., Williams, K. D., and Richardson, R. (2004). How low can you go? Ostracism by a computer is sufficient to lower self-reported levels of belonging, control, self-esteem, and meaningful existence. J. Exp. Soc. Psychol. 40, 560-567. doi: 10.1016/j.jesp.2003.11.006

Zeigler-Hill, V. (2010). The interpersonal nature of self-esteem: do different measures of self-esteem possess similar interpersonal content? J. Res. Pers. 44, 22-30. doi: 10.1016/j.jrp.2009.09.005

Zink, C. F., Tong, Y., Chen, Q., Bassett, D. S., Stein, J. L., and Meyer-Lindenberg, A. (2008). Know your place: neural processing of social hierarchy in humans. Neuron 58, 273-283. doi: 10.1016/j.neuron.2008.01.025

Conflict of Interest Statement: The authors declare that the research was conducted in the absence of any commercial or financial relationships that could be construed as a potential conflict of interest.

Copyright (C) 2016 Mahadevan, Gregg, Sedikides and De Waal-Andrews. This is an open-access article distributed under the terms of the Creative Commons Attribution License (CC BY). The use, distribution or reproduction in other forums is permitted, provided the original author(s) or licensor are credited and that the original publication in this journal is cited, in accordance with accepted academic practice. No use, distribution or reproduction is permitted which does not comply with these terms. 